\title{
Sex-Specific Differences in Running Injuries: A Systematic Review with Meta-Analysis and Meta-Regression
}

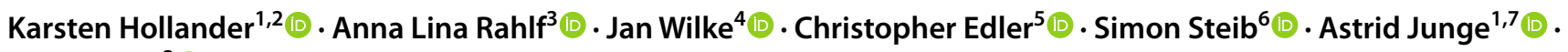 \\ Astrid Zech ${ }^{3}$ (D)
}

Accepted: 10 December 2020 / Published online: 12 January 2021

(c) The Author(s) 2021

\begin{abstract}
Background Running is a popular sport with high injury rates. Although risk factors have intensively been investigated, synthesized knowledge about the differences in injury rates of female and male runners is scarce.

Objective To systematically investigate the differences in injury rates and characteristics between female and male runners. Methods Database searches (PubMed, Web of Science, PEDro, SPORTDiscus) were conducted according to PRISMA guidelines using the keywords "running AND injur*". Prospective studies reporting running related injury rates for both sexes were included. A random-effects meta-analysis was used to pool the risk ratios (RR) for the occurrence of injuries in female vs. male runners. Potential moderators (effect modifiers) were analysed using meta-regression.

Results After removal of duplicates, 12,215 articles were screened. Thirty-eight studies were included and the OR of 31 could be pooled in the quantitative analysis. The overall injury rate was 20.8 (95\% CI 19.9-21.7) injuries per 100 female runners and 20.4 (95\% CI 19.7-21.1) injuries per 100 male runners. Meta-analysis revealed no differences between sexes for overall injuries reported per 100 runners (RR $0.99,95 \%$ CI $0.90-1.10, n=24)$ and per hours or athlete exposure (RR 0.94, 95\% CI 0.69-1.27, $n=6$ ). Female sex was associated with a more frequent occurrence of bone stress injury (RR (for males) $0.52,95 \%$ CI 0.36-0.76, $n=5$ ) while male runners had higher risk for Achilles tendinopathies (RR 1. 86, 95\% CI 1.25-2.79, $n=2)$. Meta-regression showed an association between a higher injury risk and competition distances of $10 \mathrm{~km}$ and shorter in female runners (RR 1.08, 95\% CI 1.00-1.69).
\end{abstract}

Conclusion Differences between female and male runners in specific injury diagnoses should be considered in the development of individualised and sex-specific prevention and rehabilitation strategies to manage running-related injuries.

\section{Key Points}

There were no differences between female and male runners in overall injury rates.

Female runners had more bone stress injuries.

Male runners had more Achilles tendon injuries.

Shorter competition distances increase the risk of injury for female runners.

Supplementary Information The online version contains supplementary material available at https://doi.org/10.1007/s4027 9-020-01412-7.

Karsten Hollander

karsten.hollander@medicalschool-hamburg.de

Extended author information available on the last page of the article

\section{Introduction}

Running is a very popular sport practiced all over the world. While regular physical activity and sports such as running are beneficial for prevention and rehabilitation of many health complaints ("exercise is medicine") [1, 2], running is frequently associated with high injury prevalence and incidence rates [3-5].

For injury prevention, risk factors need to be well understood [6]. Risk factors for running are manifold and consist of training load, biomechanical, anatomical and anthropometrical variables [7-12]. While some previous studies exclusively investigated either male $[9,13]$ or female [14-16] runners, sex has been suggested to be a risk factor for specific injury patterns in running, as well as for overall injury risk $[7,17,18]$. This is supported by a study investigating injury rates for female and male elite 
running athletes [19]. Analysing data collected during 14 international athletics championships, Edouard et al. [19] showed that male elite athletes had lower injury incidence rates for bone stress injuries (BSI) than female counterparts. However, injury risks differed between sexes for running disciplines (from middle distances upwards) although only with a small to trivial relative risk (1.5 for middle distances, 0.9 for long distances and 1.3 for marathon running) [19].

Including and investigating both sexes in running injury research is in line with evidence for the different risks between female and male athletes for specific types of injuries such as anterior cruciate ligament ruptures or concussions in different team sports as well as ankle sprains in all sports [20-22]. However, considering the current literature, it is difficult to derive conclusive summaries about differences in overall or specific injury epidemiology for both sexes in specific sports [18]. To develop and optimize individualized prevention and treatment options for running injuries, it is crucial to understand if and to what extent injury epidemiology differs between the sexes. Therefore, the aim of this systematic review was to evaluate the differences in injury rates and characteristics between male and female runners using meta-analytical techniques. First, differences in overall injury rates were compared between both sexes. Secondly, depending on the availability of sufficient data, specific injury diagnoses were analysed regarding their occurrence in female and male runners.

\section{Methods}

This study was conducted and presented according to the PRISMA guidelines for reporting systematic reviews and meta-analysis [23]. Prior to the start of the study, the review protocol was registered in the PROSPERO database (CRD4201911883).

\subsection{Search Strategy and Inclusion Criteria}

Two independent investigators (K.H. and C.E.) conducted a systematic literature search including articles from inception till April 2020. Prospective cohort studies and randomized controlled trials investigating healthy runners from different age groups were included. The search was restricted to articles from peer-reviewed journals published in English, German, or Spanish languages. Furthermore, studies had to report rates of running-related injuries for both sexes. Overall injury rates and injury rates for specific locations, diagnoses or injury mechanisms were considered. Included running disciplines were middle distance and long-distance track as well as cross-country, trail and road running. There was no restriction to a specific injury definition. Reviews, systematic reviews, commentaries, case studies, case series, cross-sectional studies, retrospective studies and interventional arms of randomised controlled trials (RCT) were excluded. For RCTs, only untreated control groups were considered.

The search strategy using specific keywords (running AND injur*) was applied to four different databases (PubMed, Web of Science, PEDro, SPORTDiscus). All databases were searched to identify relevant studies based on keywords, title and abstract. Two independent investigators (C.E. and K.H.) extracted relevant studies based on the inclusion criteria first by reading the title, the abstract and the full text, if available. A third reviewer (A.Z.) was available for consensus decisions. The bibliographical information of included articles was examined for further relevant references (backward search). A forward search was done via citation tracking using Web of Science $囚$ (Thomson Reuters).

\subsection{Data Extraction}

Study characteristics (design, running discipline, population, age and number of participants) as well as prevalence and incidence rates for both sexes were extracted. For prevalence rates, number of injuries or number of injured runners were related to the number of runners investigated. For incidence rates, number of injuries and specific exposures (in hours, kilometres or athlete exposure) were used. An athlete exposure (AE) is defined as one athlete participating in one practice or competition [24]. When it was not possible to extract the data from an article for specific running distances (e.g., pooling of overall injuries for track disciplines), corresponding authors were contacted by email to obtain the data. If specific data were not able to be obtained, the respective study was included in the systematic review but not in subsequent analyses.

\subsection{Study Quality Assessment}

Due to insufficient study quality assessment tools in sports injury epidemiology, a new tool was developed by consensus of K.H., A.J., A.L.R., A.Z. and S.S. on the basis of previously used tools $[20,22,25,26]$. The modification ensured that all relevant points regarding the quality of the study design and important content-related information would be considered-e.g., differences in methodological approaches such as competition or season, or the type of data collection.

This tool consisted of 15 items on recruitment, reporting, injury and exposure collection, injury definition and dropout (Table 1).

The identified quality score was used to determine a high (above the median) or low (below the median) study quality of the studies investigated (median score was 18). Two independent reviewers (K.H., A.J.) with a third reviewer (A.L.R.) for consensus assessed the study quality of the included studies. 
Table 1 Risk of bias assessment tool

\begin{tabular}{|c|c|}
\hline Question & Rating \\
\hline $\begin{array}{l}\text { Are the sources and methods of participant recruitment clearly } \\
\text { described? }\end{array}$ & Yes (1), no (0) \\
\hline $\begin{array}{l}\text { Are the relevant characteristics (n, age, sex, sport, level of competition) } \\
\text { of the study population reported? }\end{array}$ & Yes (1), no (0) \\
\hline Does the study cover season and/or tournaments/championships? & Season (2), tournaments (1), not reported (0) \\
\hline Are exposure data recorded? & Yes (1), no (0) \\
\hline Is the frequency of data collection reported? & Yes (1), no (0) \\
\hline If yes: & $\geq$ Daily (3), $\geq$ weekly (2), $\geq$ monthly (1), not reported (0) \\
\hline Is a clear injury definition provided? & Yes (1), no (0) \\
\hline If yes: & Medical attention (3), time loss (2), other (1), no clear definition (0) \\
\hline Is the method for assessing exposure described? & Yes (1), no (0) \\
\hline If yes: & Individual data collection (2), exposure estimated (1), not reported (0) \\
\hline Is the method for assessing injury reported? & Yes (1), no (0) \\
\hline If yes: & $\begin{array}{l}\text { Briefed medical personnel (3), medical personnel (2), coach, self- } \\
\text { report, media reports (1), not reported (0) }\end{array}$ \\
\hline $\begin{array}{l}\text { Are characteristics of injury reported (location, type, mechanism, sever- } \\
\text { ity, recurrent)? }\end{array}$ & Yes (1), no (0) \\
\hline If yes: & Complete (2), partly (1), no (0) \\
\hline Is the drop out $<30 \%$ drop out? & Yes (1), no (0) \\
\hline
\end{tabular}

Publication bias was checked by visual inspection of funnel plots (log risk ratio against standard errors) and regression test for funnel plot asymmetry.

\subsection{Data Synthesis and Statistics}

To compare injury risk between male and female runners, risk ratios ( $\mathrm{RR}$ ) with $95 \%$ confidence intervals $(\mathrm{CI})$ were computed for each study. Meta-analytic pooling was done using a random-effects model (DerSimonian and Laird method [27]). Between-study heterogeneity was estimated using Cochran's $Q$ and $I^{2}$ statistics. To reveal potential publication biases, funnel plots were constructed if more than ten studies were available [28]. Besides visually checking their symmetry, Egger's regression test was applied.

Following the calculation of pooled RRs, we used a mixed-effects meta-regression model to identify variables potentially affecting the outcome of the meta-analysis [27]. The choice of tested moderators (effect modifiers) was based on three criteria: (1) a plausible impact on the tested variables, (2) reporting in the included studies, (3) sufficient variation of the moderators' values [29]. The following moderators were submitted into the meta-regression model: performance/expertise level (recreational: no competitions, competitive: participating in local competitions, elite: qualifying for national or international competitions); age (youth: $<18$, adult: $\geq 18$ ) competition distance $(\leq 10 \mathrm{~km},>10 \mathrm{~km})$; study quality (low: study quality score $<18$, high: study quality score $\geq 18$ ), training duration (low: $<7.5 \mathrm{~h}$ or high: $\geq 7.5 \mathrm{~h} /$ week), training mileage (low: $<64 \mathrm{~km} /$ week, high: $\geq 64 /$ week). Moderator analyses were performed if ten or more studies were available [28]. If a significant moderator was detected, a subgroup analysis comparing the respective values of the moderator was performed using the meta-analytic procedures described above.

All calculations were performed using algorithms of the metaphor package embedded in R ( $R$ Foundations for Statistical Computing, Vienna, Austria) as well as the software JAMOVI [30] and OpenMeta [Analyst] software (OS $\mathrm{X}$ version 10.12 obtained from http://www.cebm.brown .edu/openmeta/).

\section{Results}

\subsection{Search Results}

The search returned 15,914 studies and 29 additional studies were identified through other sources. After removing 3699 duplicates and applying inclusion criteria, a total of 38 studies were considered eligible [7, 19, 24, 31-65]. Thirty-one of them could be included in the quantitative analysis. Seven studies reported on the same data sets as other included studies and were excluded from the quantitative analysis [19, 31-33, 39, 40, 65]. The full literature search process is displayed in Fig. 1. 


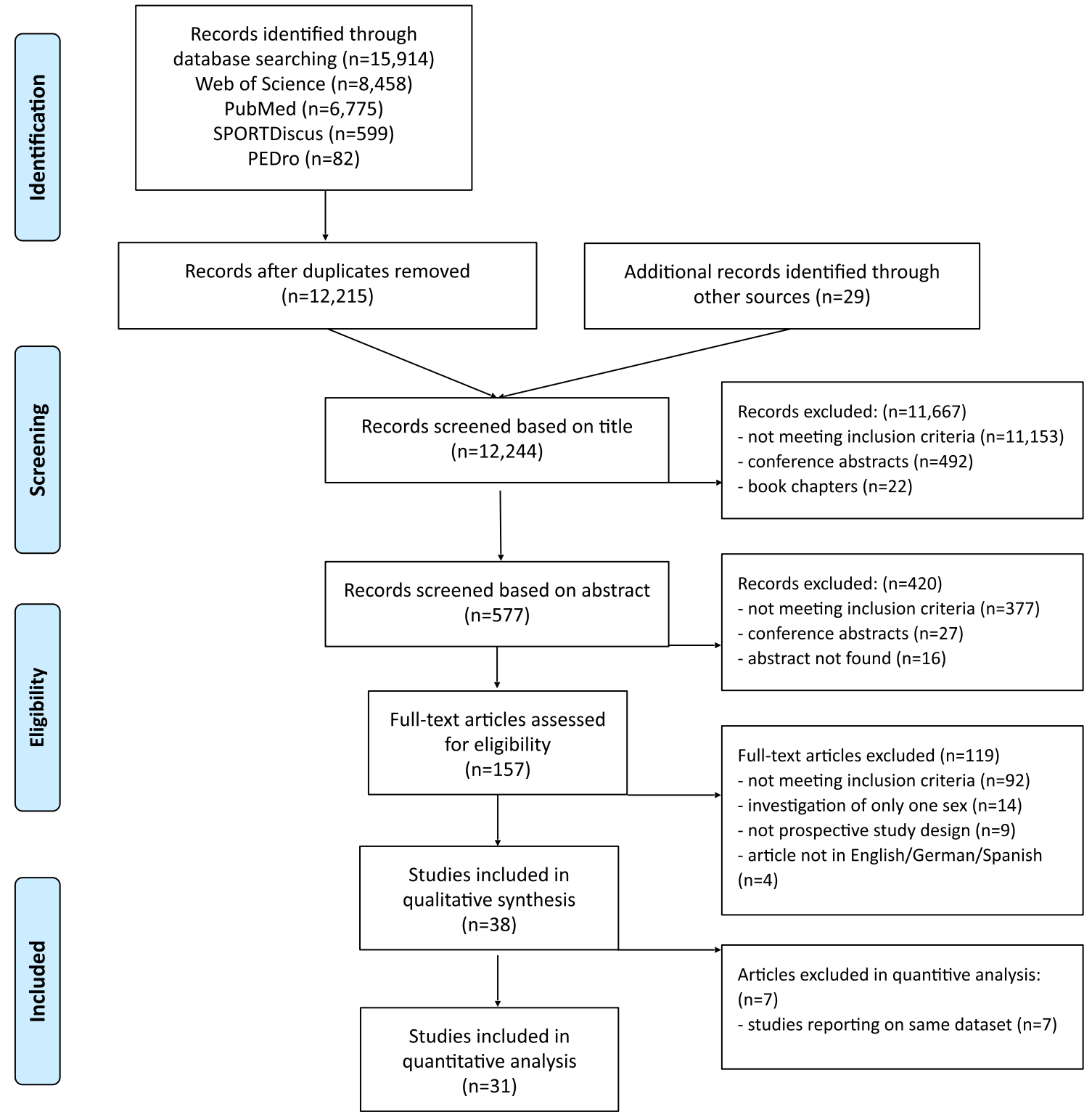

Fig. 1 Flow diagram displaying the literature search

\subsection{Characteristics of Included Studies}

Of the included studies, 36 reported injury data from 35,689 participants ( $40.8 \%$ female). Two studies reporting on injuries from the National Collegiate Athletic Association (NCAA) database did not state the number of athletes but did report the athlete exposure $(242,244$ athlete exposures with $46.7 \%$ females [24] and 276,207 athlete exposures with $50.7 \%$ females [59]). Most studies were prospective cohort studies $(n=37)$, while the control group (not receiving any intervention) from one randomised controlled study met the inclusion criteria [42]. Twenty-three studies investigated road runners, 11 track runners (middle and long distance), 10 cross-country runners and 3 studies reported on trail running/orienteering (Table 2). Studies from major competitions (European or World Championships) reported concurrently on track and road running (half or full marathon) [19, 31-33, 41]. Regarding competition level, 18 studies reported on novice and recreational runners, 11 on competitive and 9 on elite runners. Study characteristics of all included studies are summarized in Table 2.

\subsection{Study Quality}

The two independent reviewers evaluating study quality agreed on 441 of 570 evaluated items (agreement $=77.4 \%$ ). The scores for study quality ranged between 9 and 23 out of 24 points with a median of 18 and a mean \pm SD of $16.8 \pm 4.1$. 


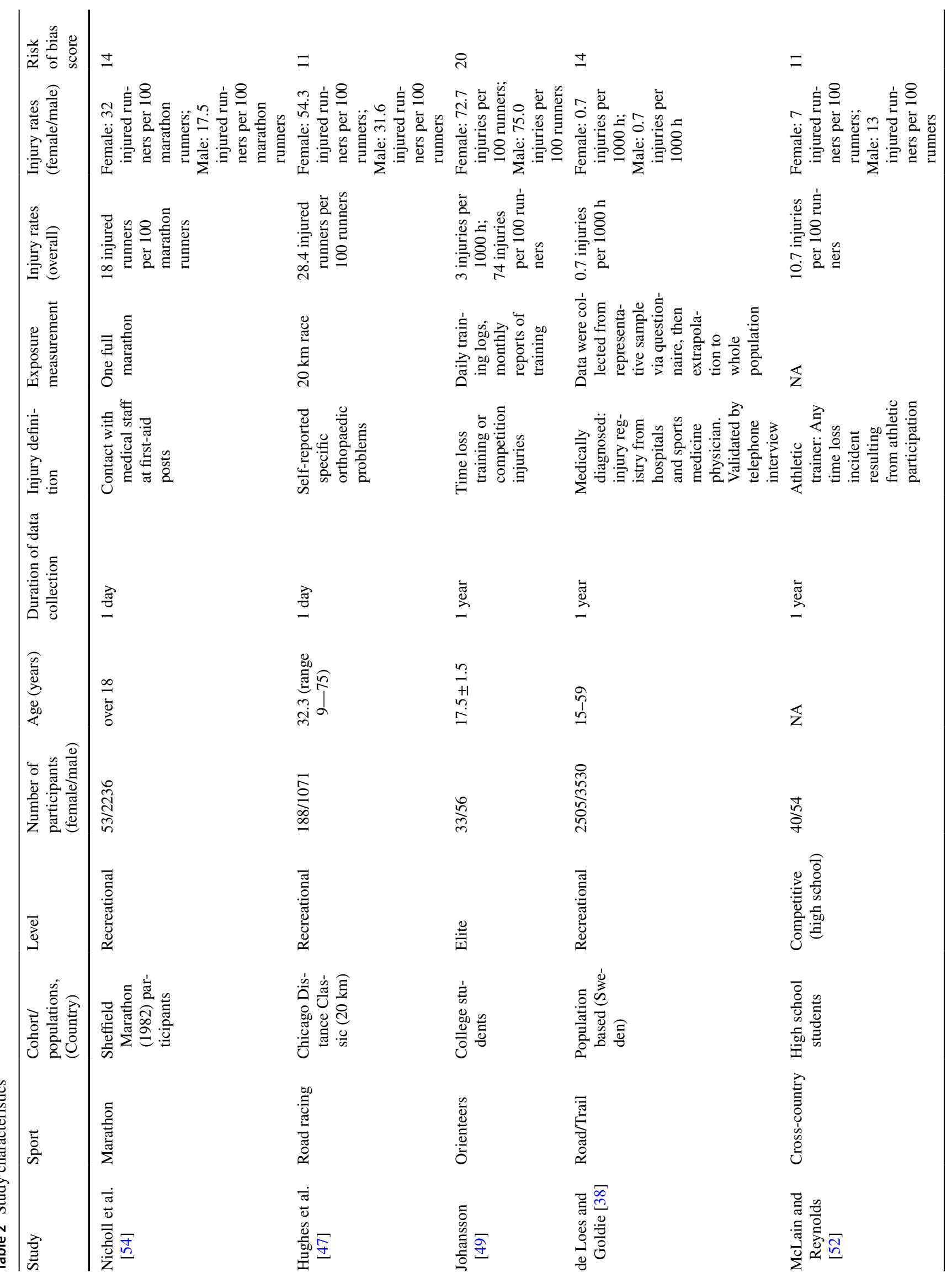




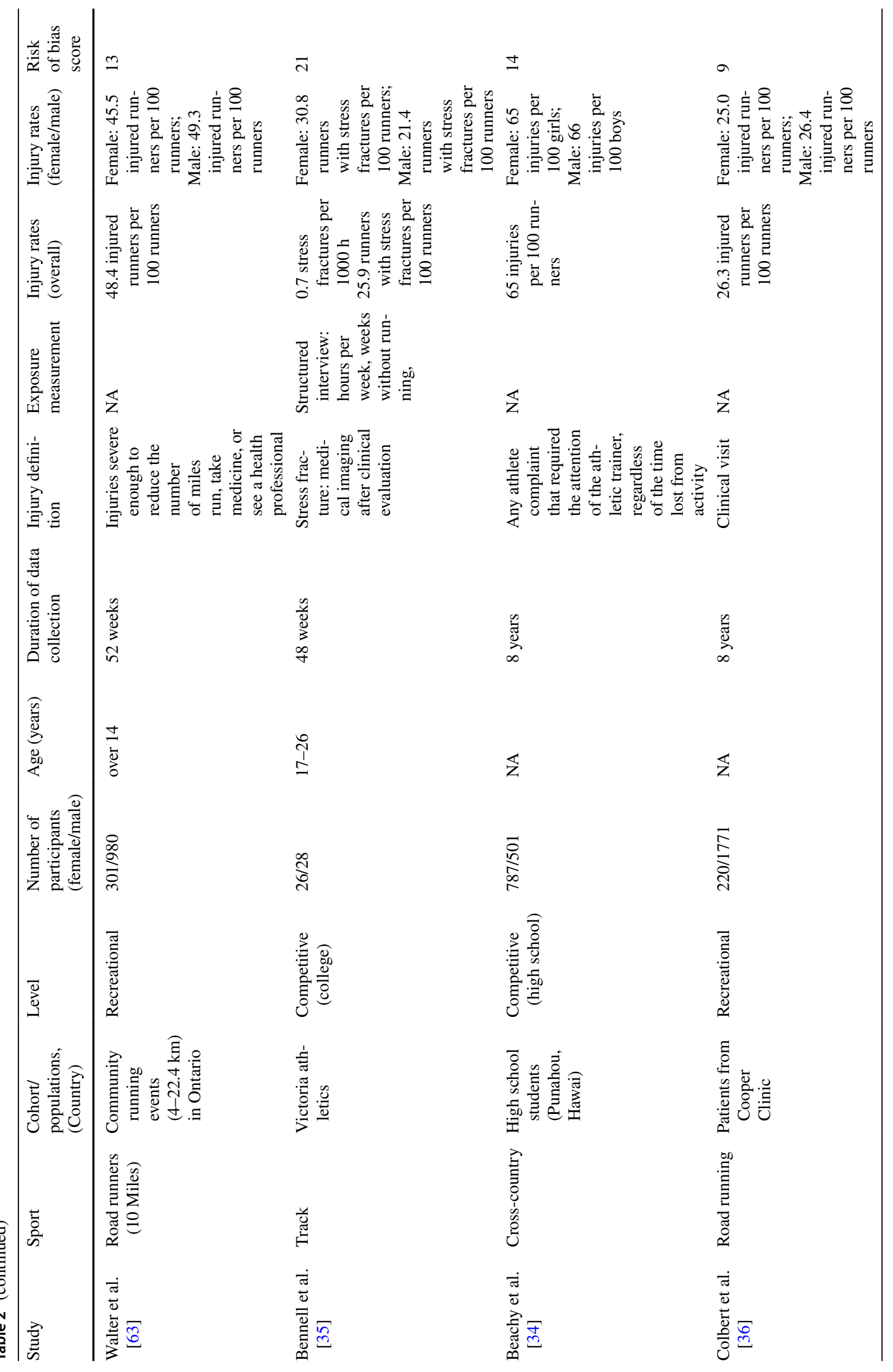




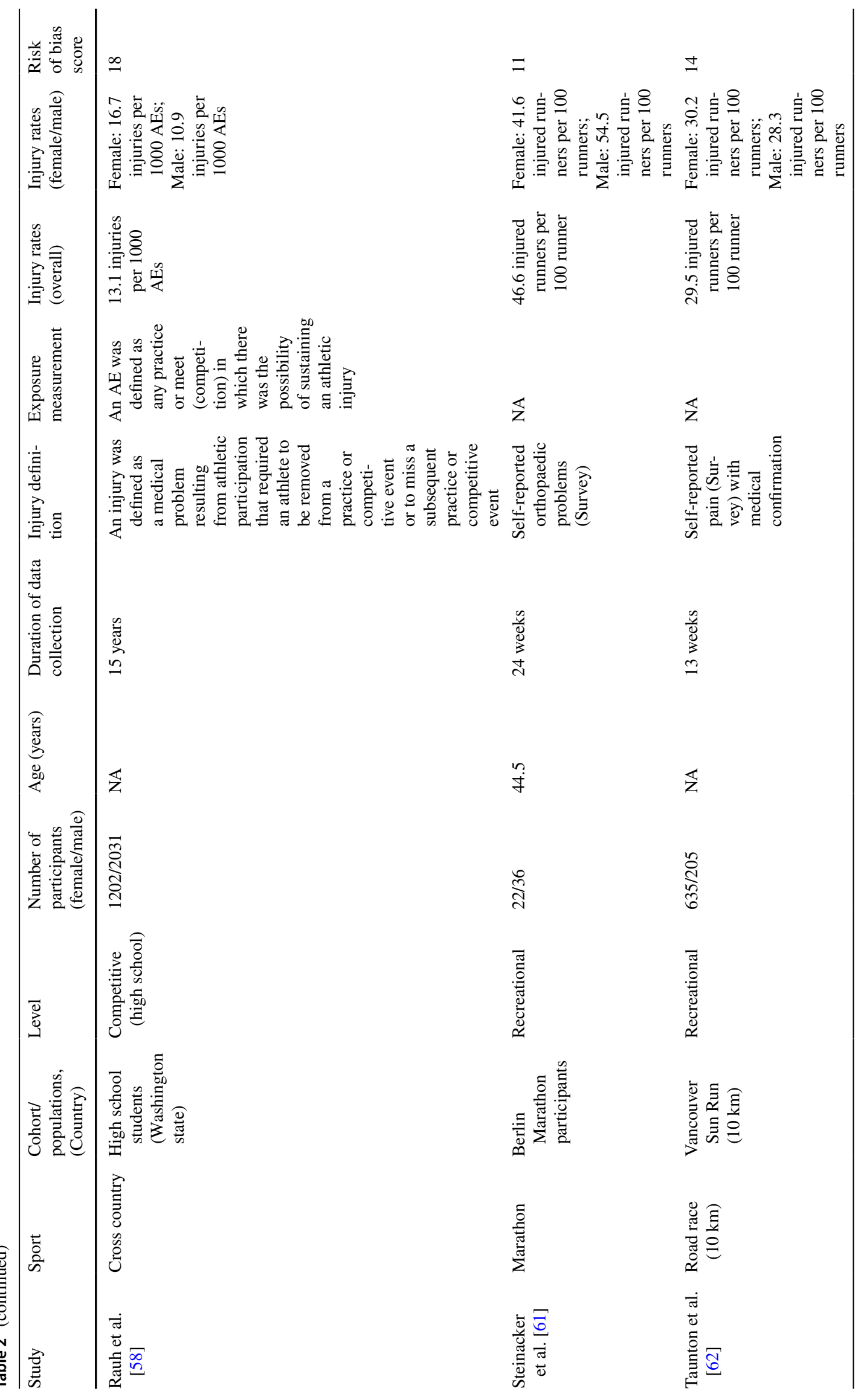




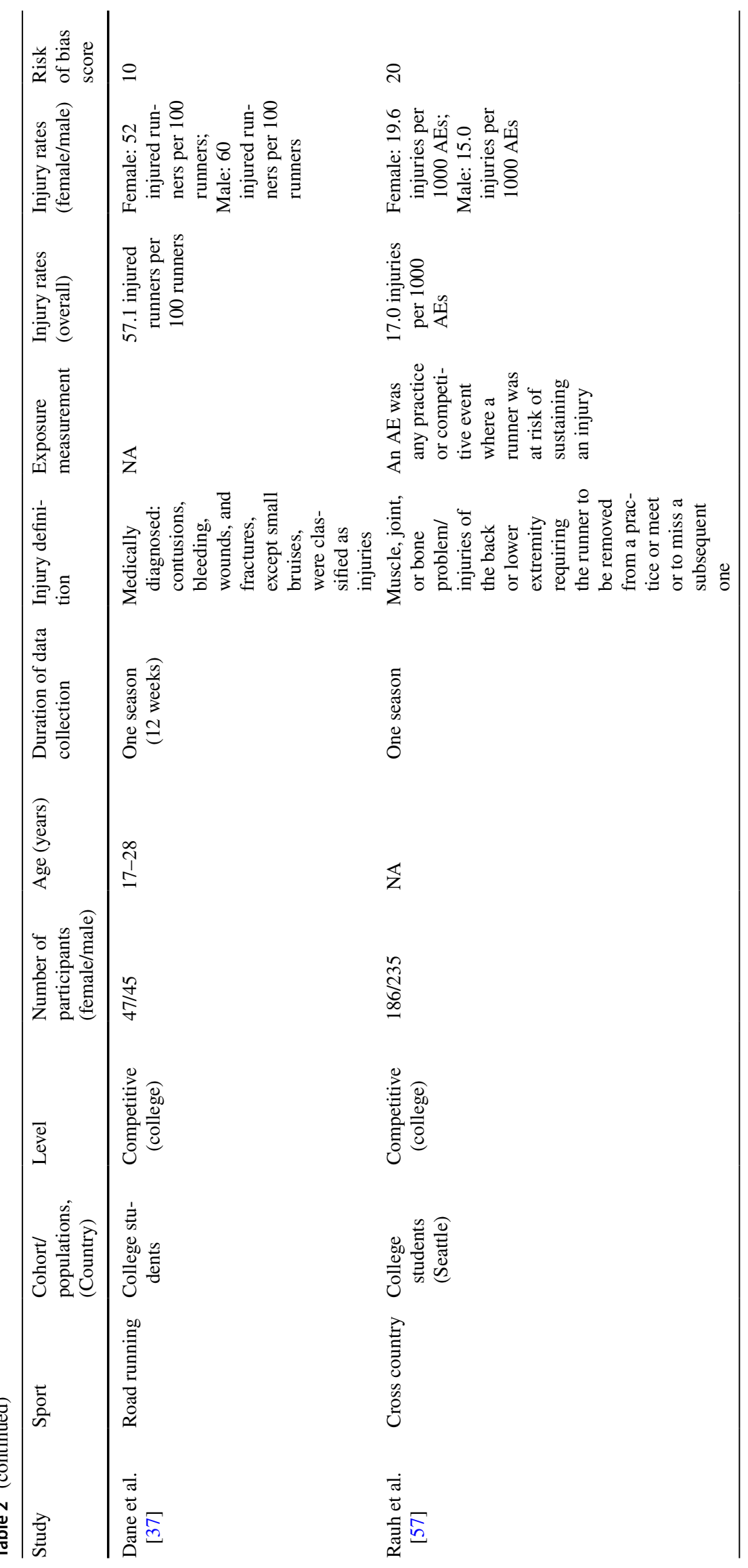




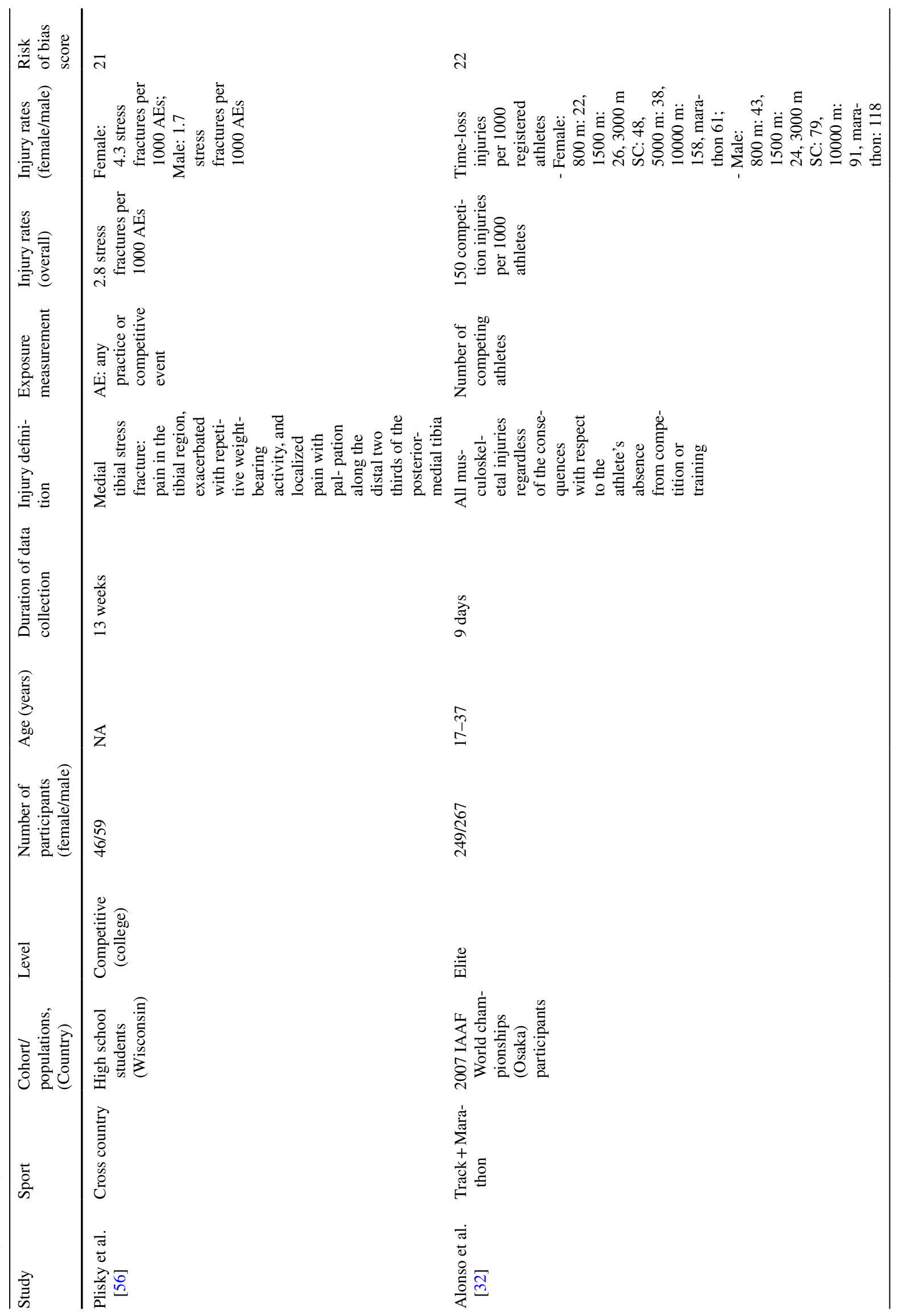




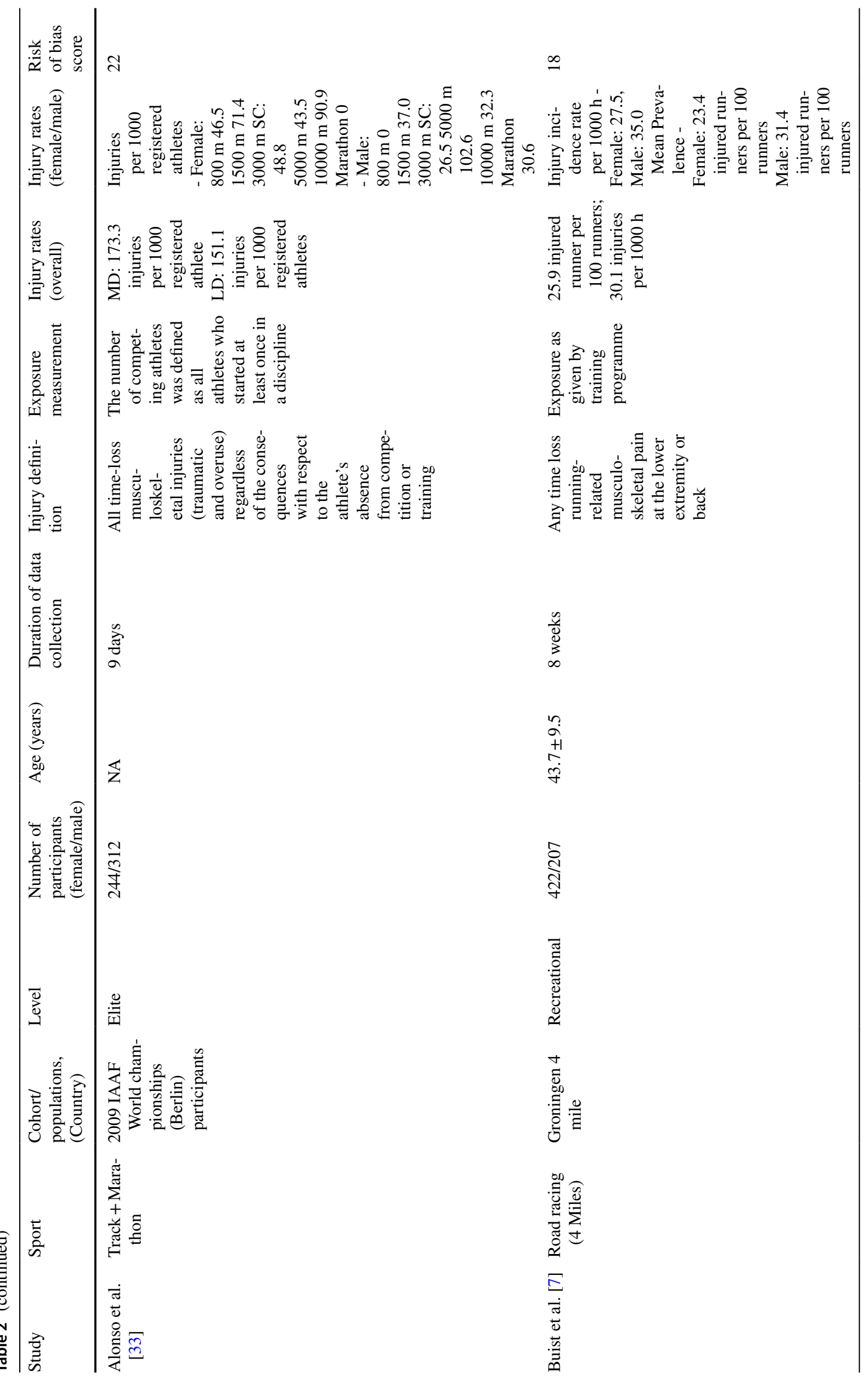


Sex-Specific Differences in Running Injuries

1021

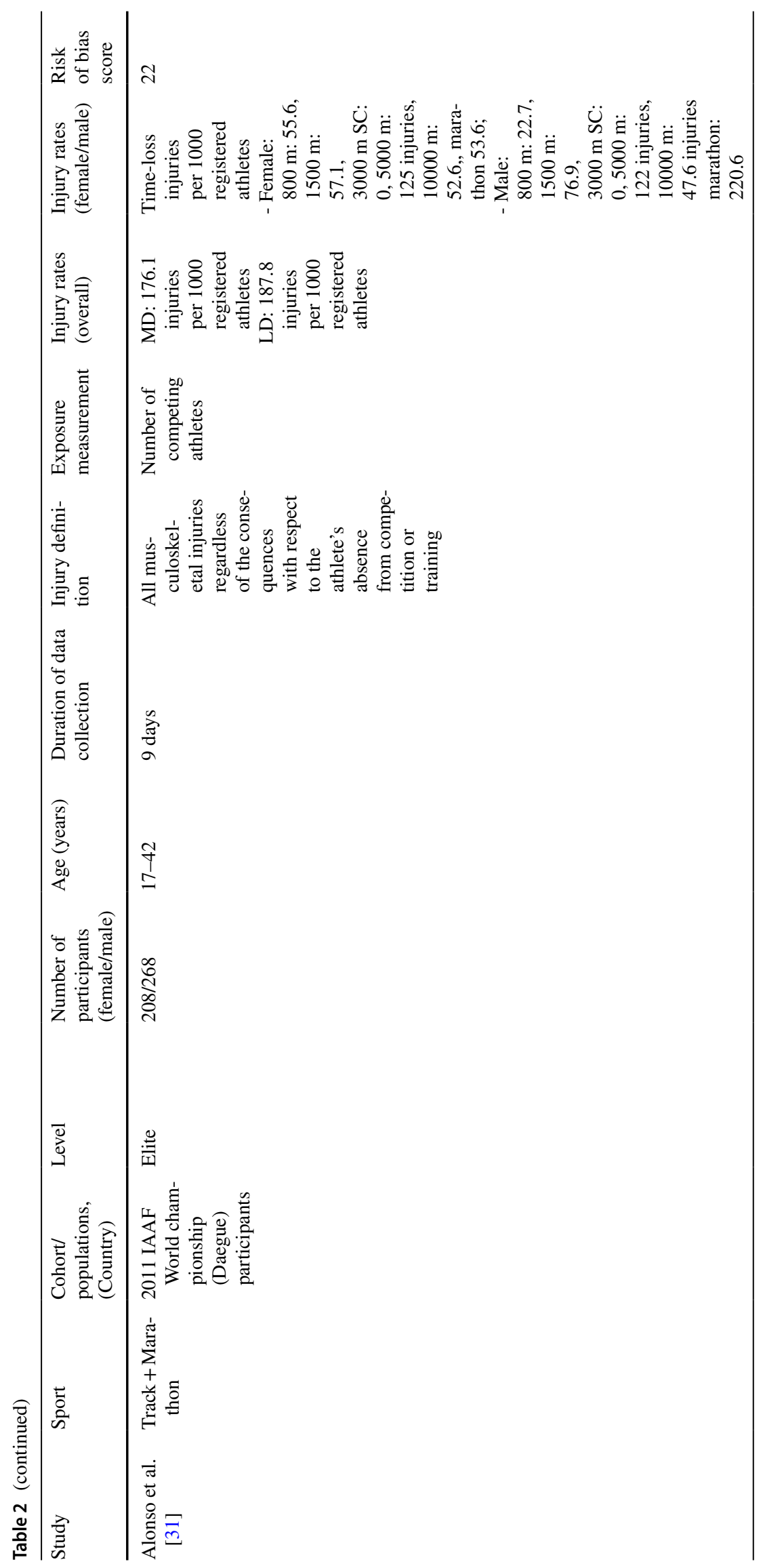




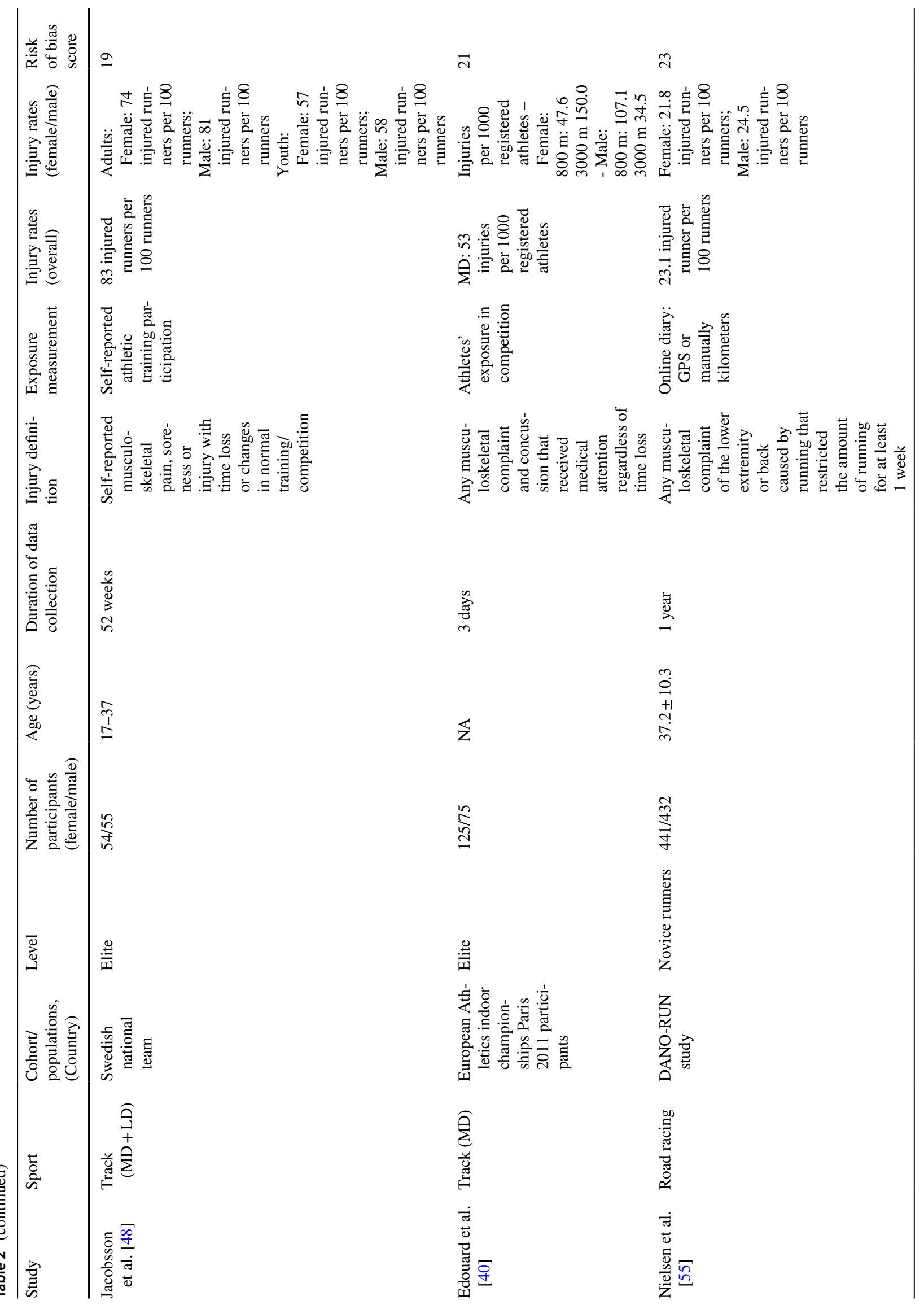




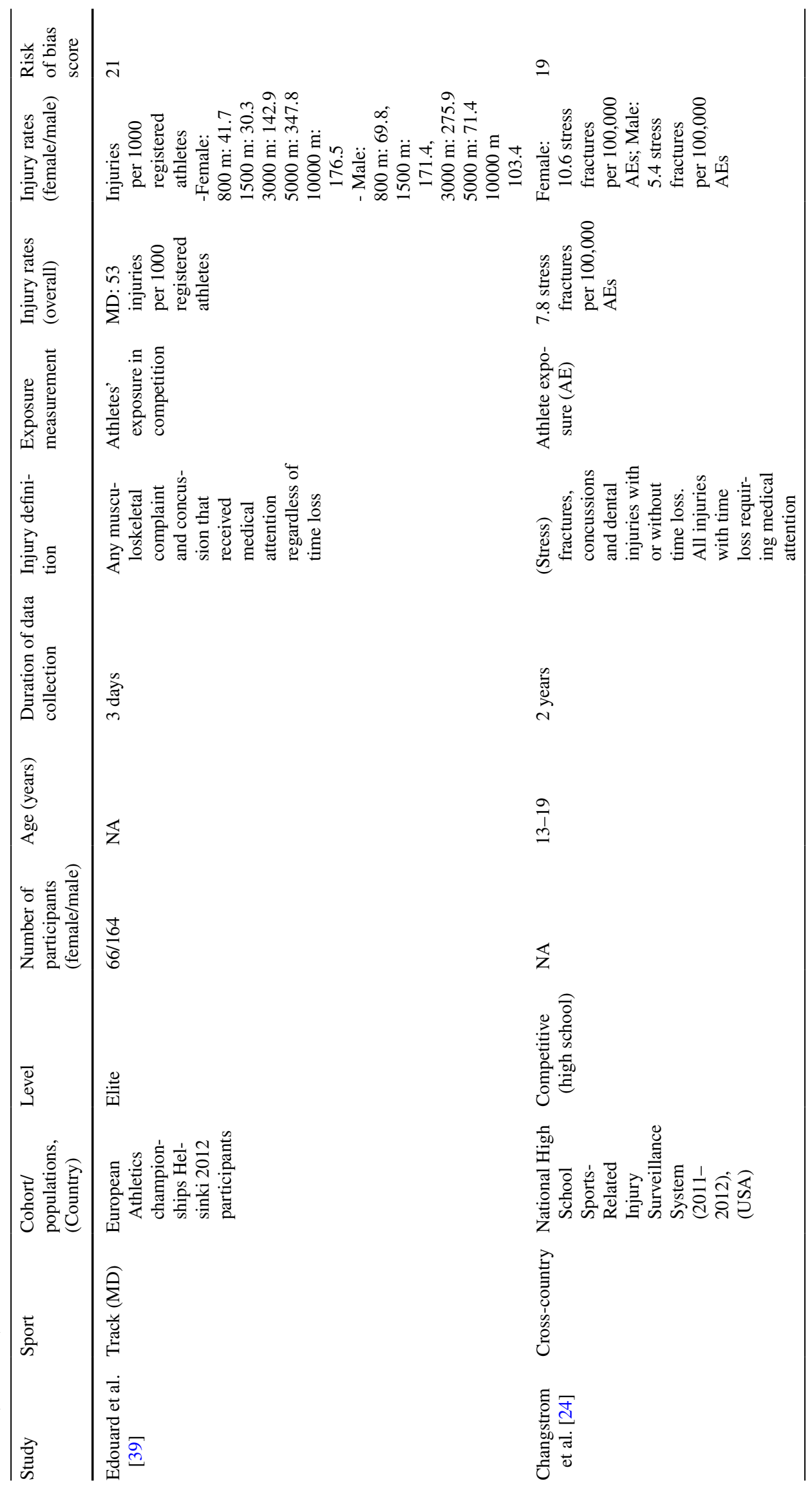




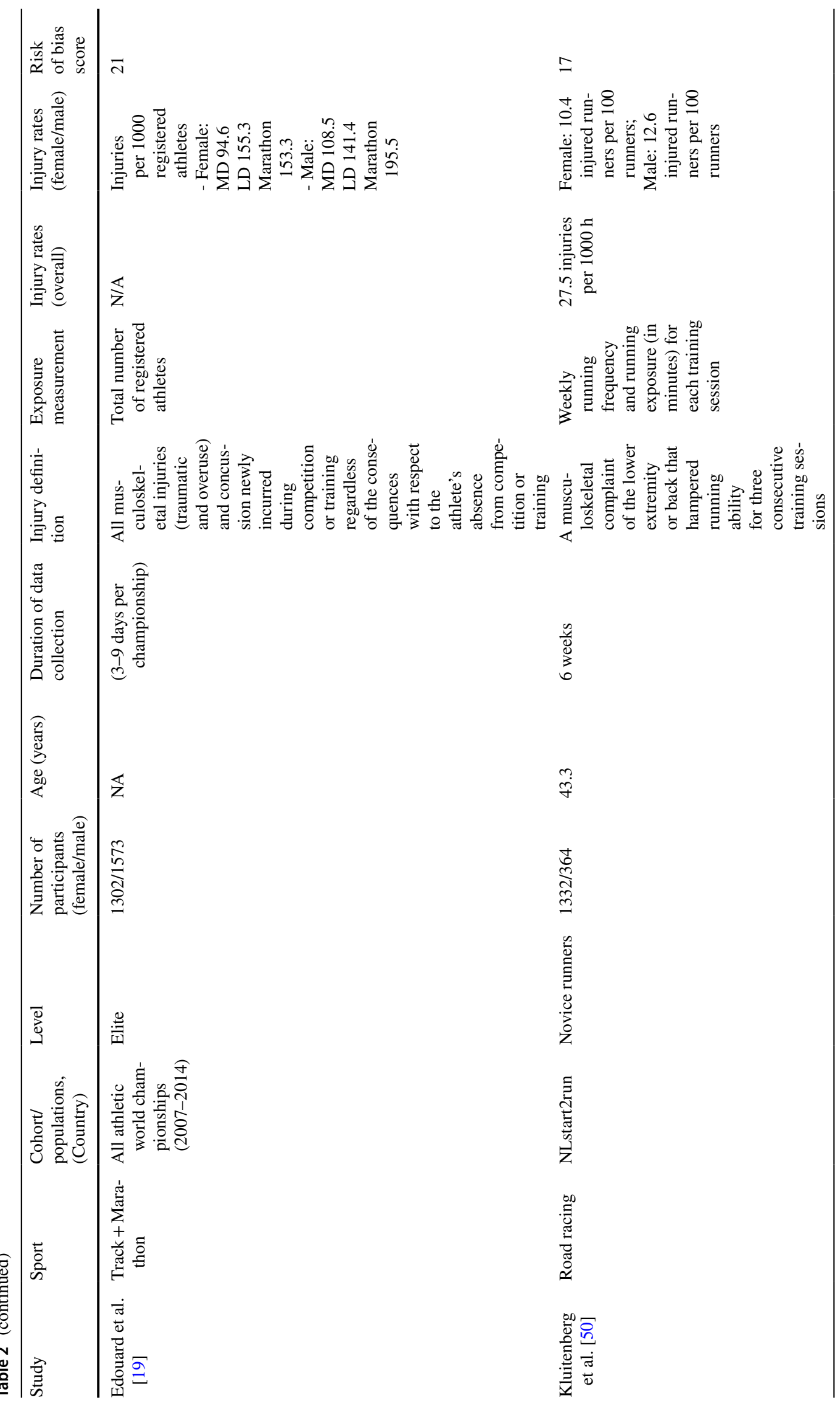


Sex-Specific Differences in Running Injuries

1025

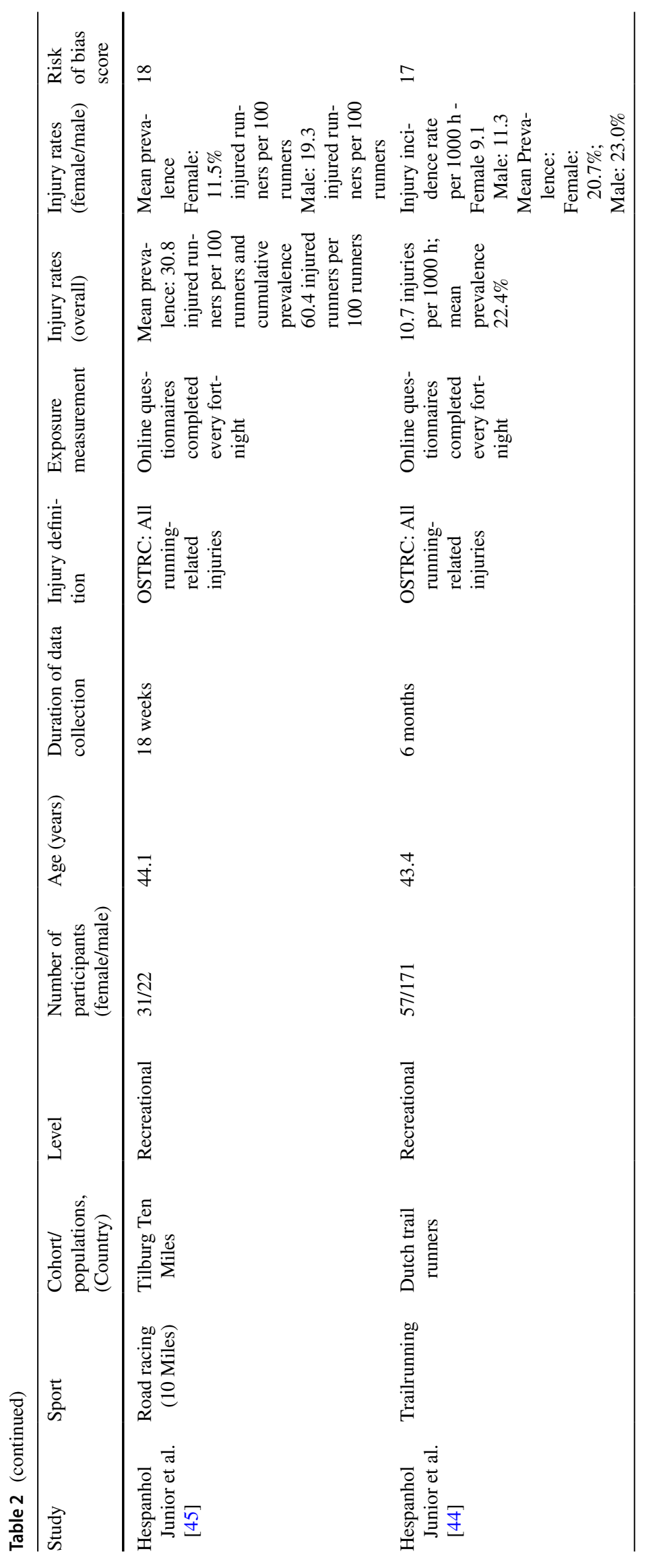




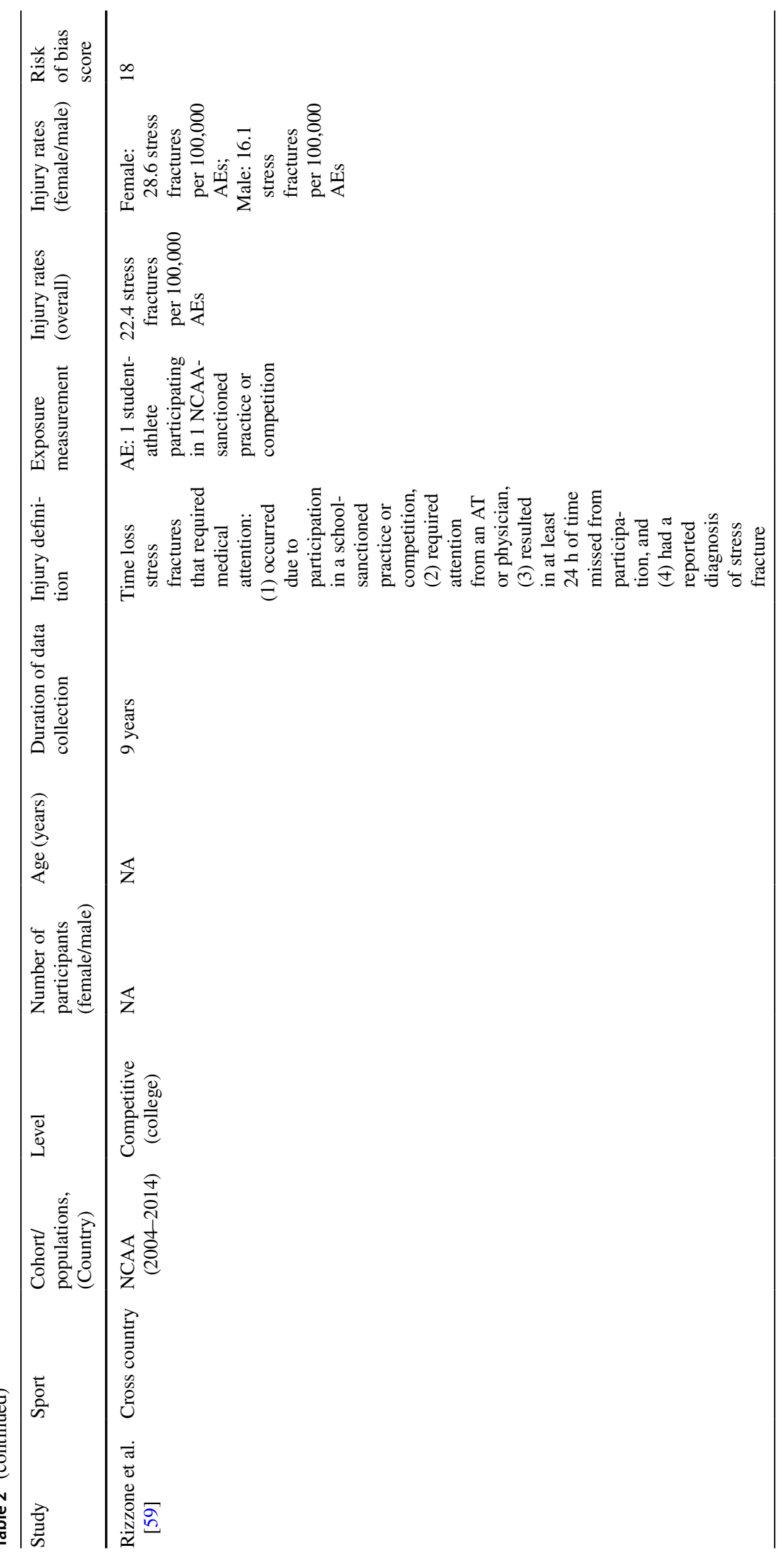




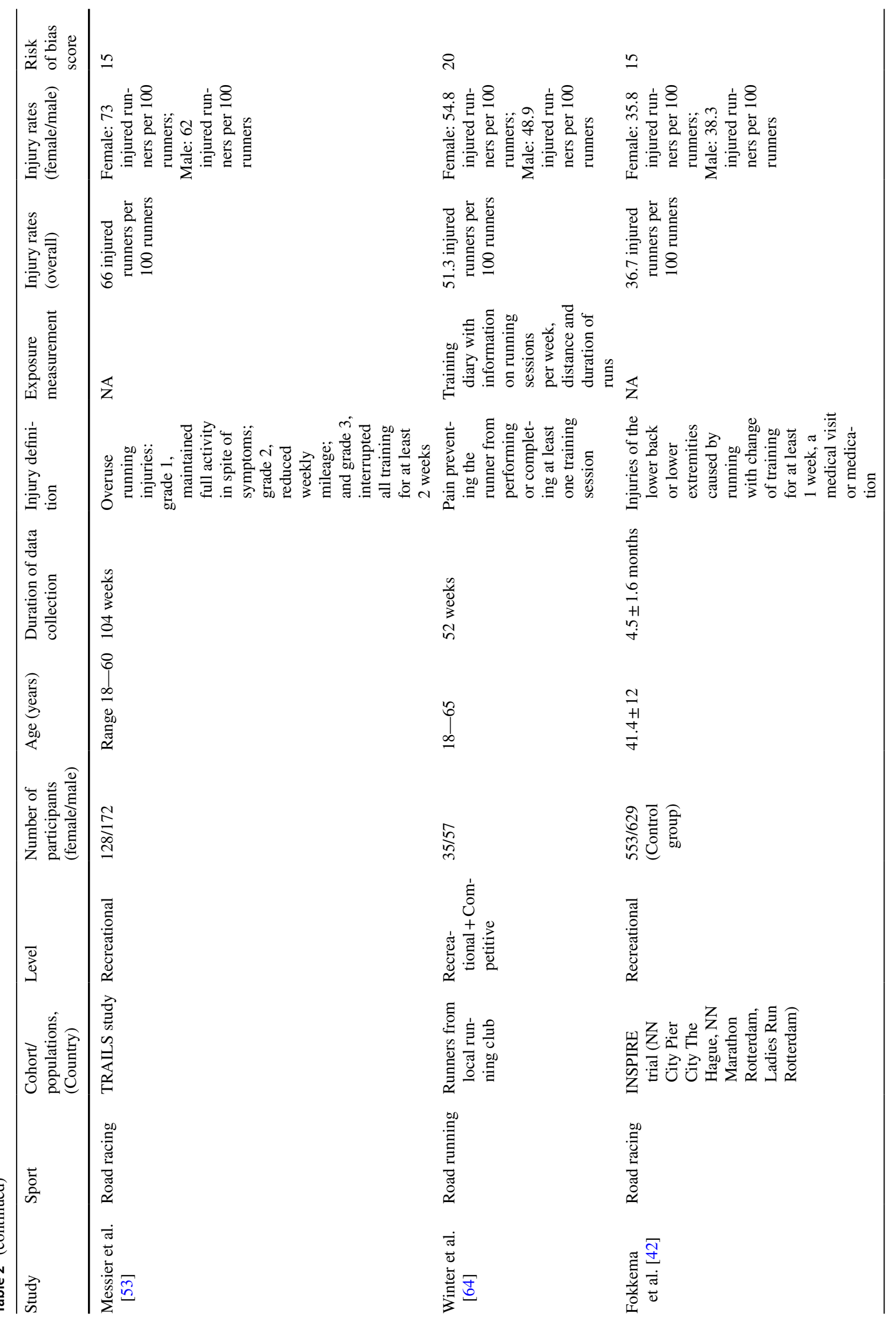




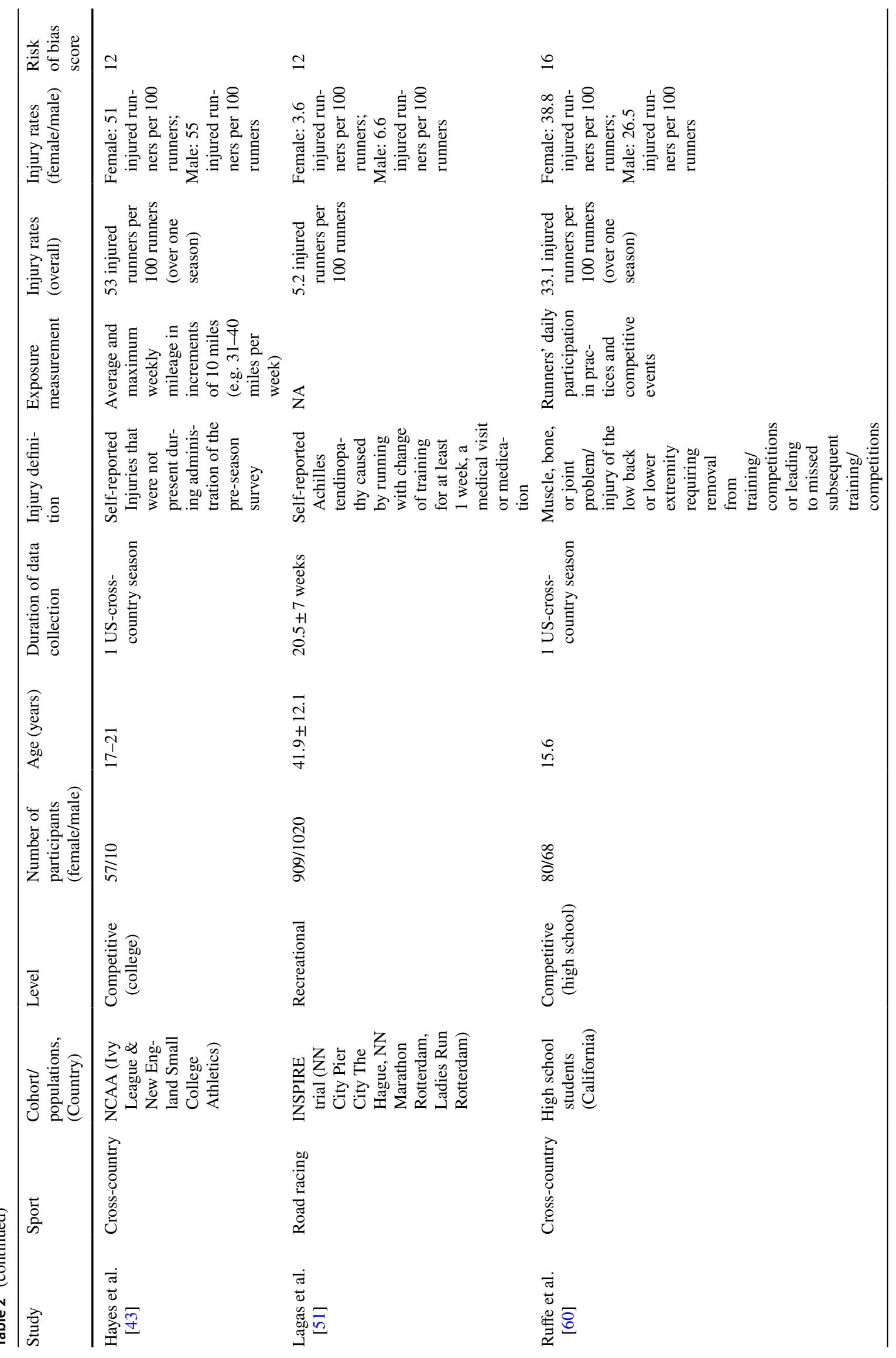




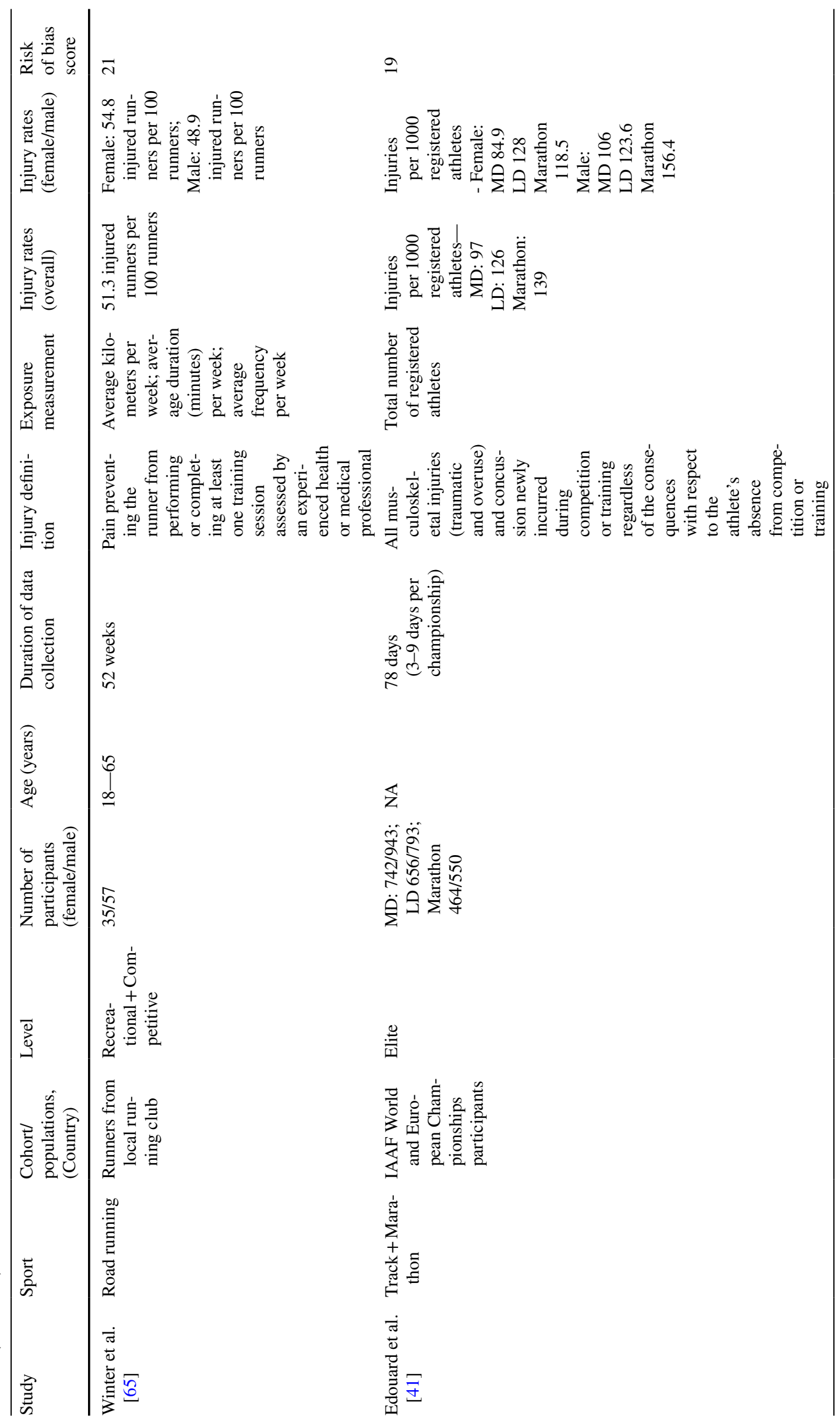



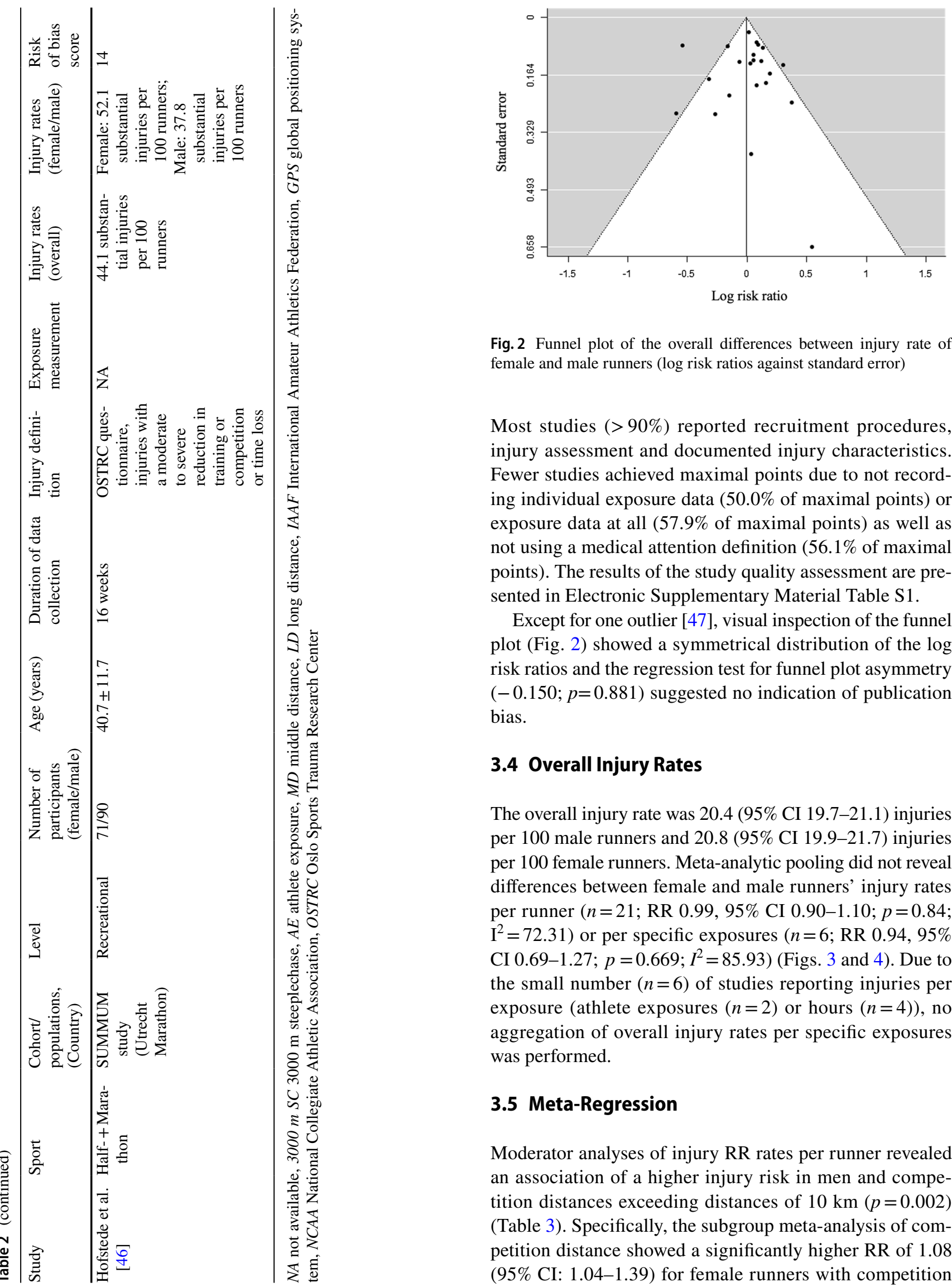

Fig. 2 Funnel plot of the overall differences between injury rate of female and male runners (log risk ratios against standard error)

Most studies (>90\%) reported recruitment procedures, injury assessment and documented injury characteristics. Fewer studies achieved maximal points due to not recording individual exposure data (50.0\% of maximal points) or exposure data at all (57.9\% of maximal points) as well as not using a medical attention definition $(56.1 \%$ of maximal points). The results of the study quality assessment are presented in Electronic Supplementary Material Table S1.

Except for one outlier [47], visual inspection of the funnel plot (Fig. 2) showed a symmetrical distribution of the log risk ratios and the regression test for funnel plot asymmetry $(-0.150 ; p=0.881)$ suggested no indication of publication bias.

\subsection{Overall Injury Rates}

The overall injury rate was 20.4 (95\% CI 19.7-21.1) injuries per 100 male runners and 20.8 (95\% CI 19.9-21.7) injuries per 100 female runners. Meta-analytic pooling did not reveal differences between female and male runners' injury rates per runner $(n=21$; RR $0.99,95 \%$ CI $0.90-1.10 ; p=0.84$; $\left.\mathrm{I}^{2}=72.31\right)$ or per specific exposures $(n=6$; RR $0.94,95 \%$ CI 0.69-1.27; $p=0.669 ; I^{2}=85.93$ ) (Figs. 3 and 4). Due to the small number $(n=6)$ of studies reporting injuries per exposure (athlete exposures $(n=2)$ or hours $(n=4)$ ), no aggregation of overall injury rates per specific exposures was performed.

\subsection{Meta-Regression}

Moderator analyses of injury RR rates per runner revealed an association of a higher injury risk in men and competition distances exceeding distances of $10 \mathrm{~km}(p=0.002)$ (Table 3). Specifically, the subgroup meta-analysis of competition distance showed a significantly higher RR of 1.08 (95\% CI: 1.04-1.39) for female runners with competition 


\section{Study}

Nicholl \& Williams [54]

Hughes et al. [47]

Johansson [49]

de Loes \& Goldie [38]

McClain \& Revnolds [52]

Walter et al. [63]

Beachy et al. [34]

Colbert et al [36]

Steinacker et al. [61]

Taunton et al. [62]

Dane et al. [37]

Buist et al. [7]

Jacobsson et al. [48]

Nielsen et al. [55]

Kluitenberg et al [50]

Messier et al. [53]

Winter et al. [64]

Fokkema et al. [42]

Ruffe et al. [60]

Hayes et al. [43]

Edouard et al. [41]

Hofstede et al. [46]

Overall $\left(\left.\right|^{\wedge} 2=72.31 \%, P<0.001\right) \quad 0.994 \quad(0.902,1.097)$

$0.552(0.322,0.945)$

$0.582(0.497,0.681)$

$1.031(0.797,1.335)$

$1.032(0.480,2.220)$

$1.728(0.476,6.274)$

$1.083(0.942,1.244)$

$1.016(0.937,1.101)$

$1.057(0.830,1.346)$

$0.764(0.444,1.315)$

$0.936(0.730,1.199)$

$1.175(0.813,1.697)$

$1.352(1.037,1.764)$

$1.055(0.855,1.303)$

$1.127(0.885,1.436)$

$1.211(0.886,1.655)$

$0.848(0.724,0.994)$

$0.862(0.556,1.335)$

$1.098(0.944,1.277)$

$1.457(0.905,2.344)$

$1.081(0.740,1.579)$

$1.146(0.967,1.358)$

$0.725(0.513,1.025)$
Estimate (95\% C.I.) Injuries/Males Injuries/Males

$256 / 2236$

$338 / 1071$

$42 / 56$

$16 / 3530$

$7 / 54$

$483 / 980$

$331 / 501$

$468 / 1771$

$15 / 36$

$58 / 205$

$27 / 45$

$65 / 207$

$43 / 55$

$106 / 432$

$46 / 364$

$106 / 172$

$21 / 43$

$241 / 629$

$26 / 68$

$22 / 40$

$284 / 2286$

$34 / 90$

$3035 / 14871$

$2048 / 9863$

$$
\begin{gathered}
11 / 53 \\
102 / 188 \\
24 / 33 \\
11 / 2505 \\
3 / 40 \\
137 / 301 \\
512 / 787 \\
55 / 220 \\
12 / 22 \\
192 / 635 \\
24 / 47 \\
98 / 422 \\
40 / 54 \\
96 / 441 \\
139 / 1332 \\
93 / 128 \\
17 / 30 \\
193 / 553 \\
21 / 80 \\
29 / 57 \\
202 / 1864 \\
37 / 71
\end{gathered}
$$

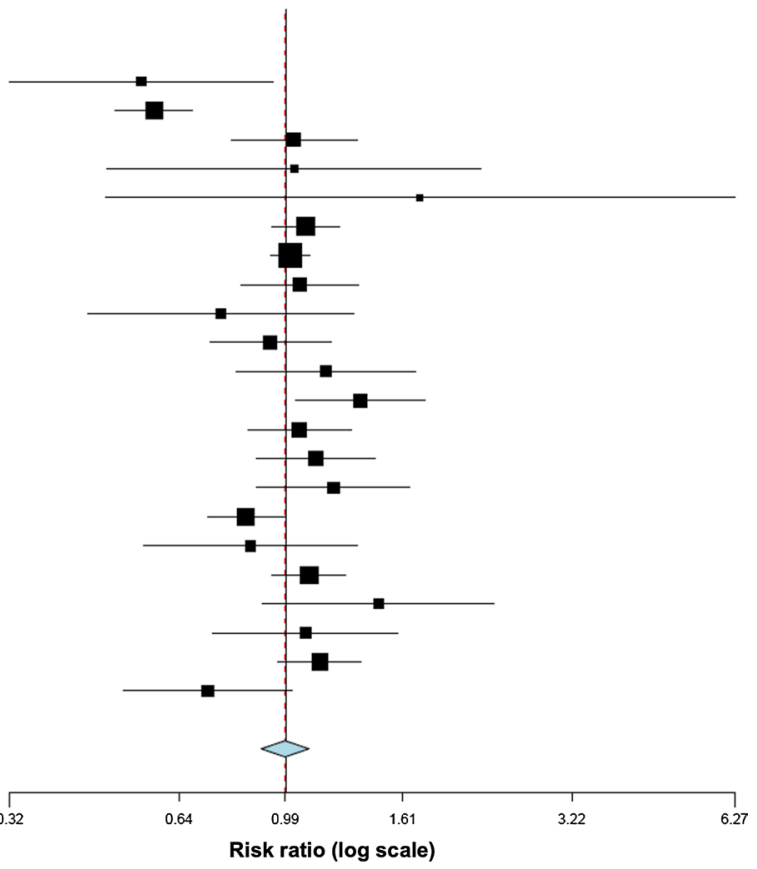

Fig. 3 Forest plot depicting the meta-analytical results comparing risk ratios for male and female runners regarding injuries per 100 runners

Study

de Loes \& Goldie [38]

Rauh et al. [58]

Rauh et al. [57]

Buist et al. [7]

Hespanhol Junior et al. [45]

Hespanhol Junior et al. [44]

Overall $\left(\left.\right|^{\wedge} 2=85.93 \%, P<0.001\right) \quad 0.937 \quad(0.694,1.263)$

$0.910(0.422,1.961)$

$0.655(0.595,0.722)$

$0.646(0.524,0.796)$

$1.273(0.935,1.733)$

$1.433(0.781,2.628)$

$1.240(0.917,1.675)$

$0.937(0.694,1.263)$
Estimate (95\% C.I.) Injuries/Males Injuries/Females
$16 / 241452$

$846 / 77491$

$159 / 10600$

$65 / 1857$

$23 / 594$

$188 / 16617$

$1297 / 348611$

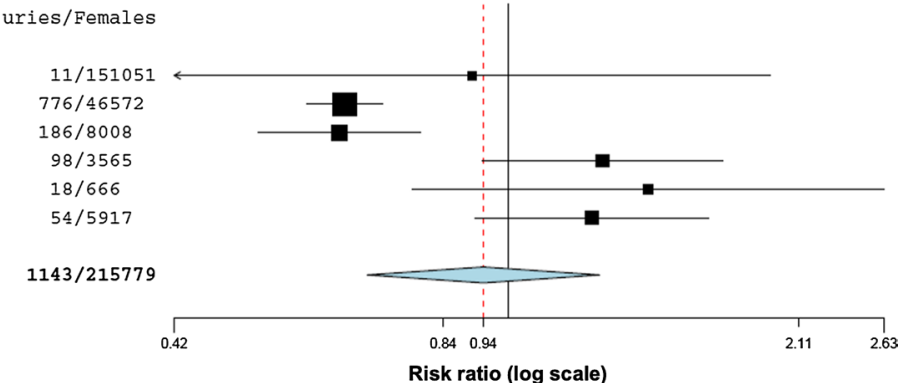

Fig. 4 Forest plot depicting the meta-analytical results comparing risk ratios for male and female runners regarding injuries per exposure (hours or athlete exposures)

distances $\leq 10 \mathrm{~km}$. For competition distances $>10 \mathrm{~km}$, the comparison approached but failed to reach significance although the RR of 0.77 (95\% CI: 0.58-1.02) was suggestive of a lower probability of injury in male runners (Fig. 5). No meta-regression was performed for specific injuries and moderators training duration or training mileage due to absence of more than ten studies reporting these variables [28].

\subsection{Specific Injury Rates}

Data for two specific running-related injuries were available for synthesis.

\subsubsection{Bone Stress Injuries}

Four studies reported on bone stress injuries with a pooled decreased probability for male runners (estimated RR $0.52,95 \%$ CI 0.36-0.76, $p<0.001 ; I^{2}=0$ ) (Fig. 6).

\subsubsection{Achilles Tendinopathy}

Furthermore, data pooling for two studies reporting injury rates for Achilles tendinopathy revealed an increased chance for male runners to have an Achilles tendon injury (estimated RR 1.86, 95\% CI 1.25-2.79, $p=0.022 ; I^{2}=0 \%$ ) (Fig. 7). 
Table 3 Results of the moderator analysis for injury risk ratio rates per 100 female or male runners

\begin{tabular}{|c|c|c|c|c|c|}
\hline Moderator & $\begin{array}{l}\text { No of com- } \\
\text { parisons (k) }\end{array}$ & $Z$ & $p$ & Risk ratio estimate $(95 \% \mathrm{CI})$ & $\mathrm{Tau}^{2} / Q$ \\
\hline Risk of bias & 22 & & & & $0.0299 / 68.1$ \\
\hline Intercept & & -0.88 & 0.378 & $-0.051(-0.167$ to 0.063$)$ & \\
\hline Moderator & & 1.42 & 0.156 & $0.151(-0.058$ to 0.359$)$ & \\
\hline Level & 20 & & & & $0.0385 / 63.1$ \\
\hline Intercept & & 0.68 & 0.495 & $0.044(-0.083$ to 0.171$)$ & \\
\hline Moderator & & 1.05 & 0.293 & $0.110(-0.095$ to 0.316$)$ & \\
\hline Age & 15 & & & & $0.0224 / 27.3$ \\
\hline Intercept & & 0.87 & 0.387 & $0.116(-0.146$ to 0.378$)$ & \\
\hline Moderator & & -0.81 & 0.419 & $-0.119(-0.407$ to 0.170$)$ & \\
\hline Competition distance & 14 & & & & $0.0311 / 44.7$ \\
\hline Intercept & & 1.71 & 0.088 & $0.144(-0.021$ to 0.309$)$ & \\
\hline Moderator & & -3.05 & 0.002 & $-0.387(-0.636$ to -0.138$)$ & \\
\hline
\end{tabular}

95\% CI 95\% confidence interval

\section{(a) Competition Distance $\leq 10 \mathrm{~km}$}

\begin{tabular}{|c|c|c|}
\hline Study & Estimate $(95 \%$ & $\% \mathrm{Cl})$ \\
\hline McLain \& Reynolds [52] & $1.728(0.476$ & $6.234)$ \\
\hline Beachy et al. [34] & $1.016 \quad 0.937$, & $1.101)$ \\
\hline Buist et al. [7] & $1.352(1.037$, & $1.764)$ \\
\hline Jacobsson et al. [48] & $1.055 \quad 0.855$ & $1.303)$ \\
\hline Nielsen et al. [55] & $1.127 \quad 0.885$ & $1.436)$ \\
\hline Kluitenberg et al. [50] & $1.211(0.886$ & $1.655)$ \\
\hline Ruffe et al. [60] & $1.453 \quad 0.905$ & $2.344)$ \\
\hline Hayes et al. [43] & $1.081(0.340$ & $1.579]$ \\
\hline Overall ( $\left(\left.\right|^{\wedge} 2=7 \%, P=0.378\right)$ & $1.081(1.000$ & 1.169) \\
\hline
\end{tabular}

Injuries/Males
$7 / 54$
$331 / 501$
$65 / 207$
$43 / 55$
$106 / 432$
$46 / 364$
$26 / 68$
$22 / 40$
$646 / 1721$

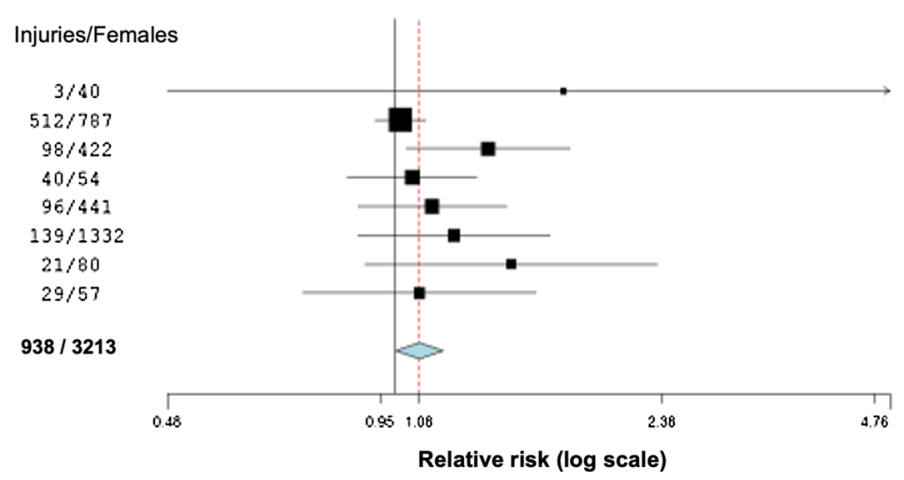

Relative risk (log scale)

\section{(b) Competition Distance $>10 \mathrm{~km}$}

\begin{tabular}{llll} 
Study & \multicolumn{3}{c}{ Estimate $(95 \% \mathrm{Cl})$} \\
Nicholl \& Williams [54] & 0.552 & $(0.322,0.945)$ \\
Hughes et al. [47] & 0.582 & $(0.497,0.681)$ \\
Walter et al. [63] & 1.083 & $(0.942,1.244)$ \\
Steinacker et al. 2001 [61] & 0.764 & $(0.444,1.315)$ \\
Taunton et al. [62] & 0.936 & $(0.730,1.199)$ \\
Hofstede et al. [46] & 0.725 & $(0.513,1.025)$ \\
Overall (I^2=87 \% , P<0.001) & $\mathbf{0 . 7 6 8}$ & $(\mathbf{0 . 5 7 8}$, & $\mathbf{1 . 0 2 2})$
\end{tabular}

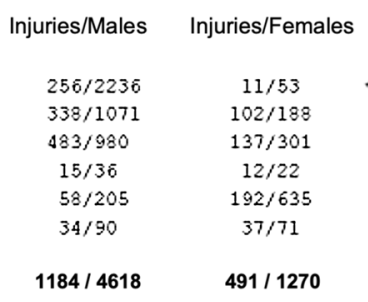

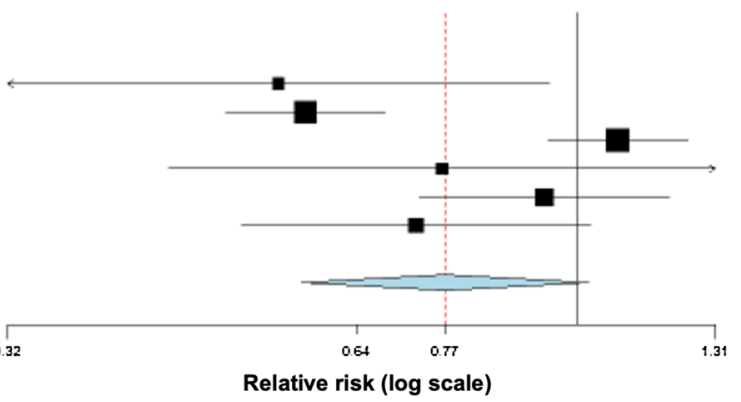

Fig. 5 Forest plot depicting the meta-analytical results for sub-analysis (competition distance) of risk ratios for male and female runners regarding injuries per 100 runners. Subgroup 1 (a) represents studies

investigating runners competing in distances below or equal to $10 \mathrm{~km}$ and subgroup 2 (b) in distances above $10 \mathrm{~km}$

running-related injury rates and characteristics. While no differences between sexes were found for overall runningrelated injuries, female runners were more likely to sustain bone stress injuries while male runner were more prone to Achilles tendinopathies. Meta-regression showed that for

The aim of this analysis was to systematically analyse the literature to reveal sex-related differences in 


\section{Study}

Johansson et al. [49] Bennell et al. [35] Plisky et al. [56]

Changstrom et al. [24]

Rizzone et al. [59]

Overall $\left(\left.\right|^{\wedge} 2=0 \%, P=0.779\right) \quad 0.523 \quad(0.359, \quad 0.763)$

$\begin{array}{cc}\text { Estimate (95\% C.I.) } & \text { Injuries/Males } \\ 2.982(0.148,60.296) & 2 / 56 \\ 0.442(0.166,1.178) & 6 / 16934 \\ 0.400(0.148,1.081) & 6 / 3452 \\ 0.510(0.201,1.295) & 7 / 129244 \\ 0.565(0.336,0.950) & 22 / 136289 \\ 0.523(0.359,0.763) & 43 / 285975\end{array}$

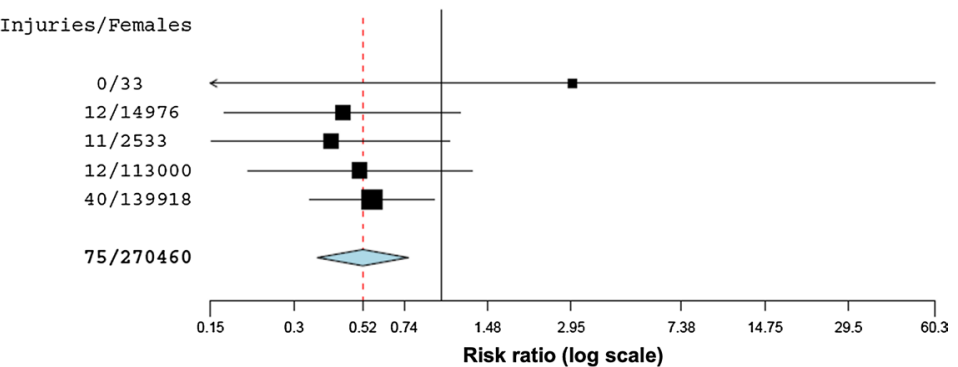

Fig. 6 Forest plot depicting the meta-analytical results comparing risk ratios for male and female runners regarding bone stress injuries

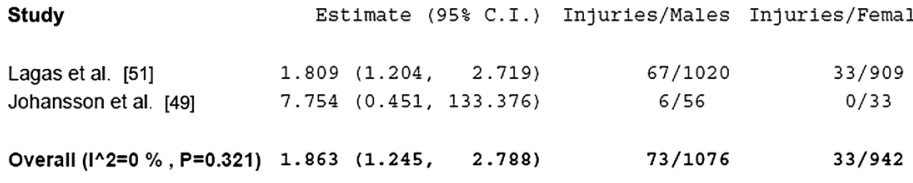

$33 / 942$

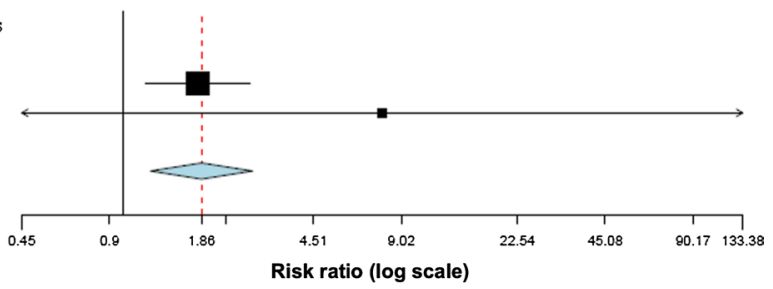

Fig. 7 Forest plot depicting the meta-analytical results comparing risk ratios for male and female runners regarding Achilles tendinopathy

competition distances of $10 \mathrm{~km}$ and shorter, female runners had higher risk for injuries than male runners.

\subsection{No Differences in Overall Injury Rates between Female and Male Runners}

Despite pooling data from all available epidemiological studies, no differences in overall injury rates between female and male runners were found in this systematic review. This was the case for both studies reporting injuries per runner and injuries per specific exposures. The injury rates of 20.4 (male) and 20.8 (female) per 100 runners are in accordance with summaries of injury rates from the last three decades [4]. Nonetheless, these rates are at the lower spectrum of published injury rates that were reported to be up to $79.3 \%$ [66].

\subsection{Shorter Competition Distances Increase the Risk of Injury for Female Runners}

Injury rates depend on several factors that need to be taken into consideration, such as systematic factors (age, BMI), running-/training-related factors (training frequency, training and racing distance, experience, level of running, footwear, biomechanics), health factors (injury history) and lifestyle factors (drinking, smoking) [66-70].

Not all of these factors were reported in each study and may vary between investigated populations. Therefore, the moderator analysis was incorporated into this study. Only competition distance was a statistically significant moderator for an increased risk of female runners compared to male runners when running competition distances of $10 \mathrm{~km}$ and shorter. Furthermore, the subanalysis revealed a tendency of increased injury risk for male runners for longer distances than $10 \mathrm{~km}$. This is in accordance with the finding that male runners had a higher risk of sustaining injuries compared to female runners when running high mileages ( $>64 \mathrm{~km} /$ week) [18]. While running higher mileages are associated with longer competition distances, this can only be used as an estimate for this discussion. Unfortunately, there was insufficient reporting of training load (time or mileage) in the included studies. For future studies reporting data on injury epidemiology or risk factors, it is strongly recommended to report the training load $[71,72]$.

\subsection{Bone Stress Injuries Occur Twice as Often in Female than in Male Runners}

Female runners had twofold higher risk of having a bone stress injury compared to male runners in this review. A bone stress injury is an injury pattern with known sex differences for epidemiology and risk factors [73]. Bone stress injuries are common running-related overuse injuries due to cumulative microtrauma to the bone [74]. Especially in younger ages, females seem to have a higher risk for bone stress injuries compared to male runners. For example, Changstrom et al. [24] reported a twofold risk and Plisky et al. [56] a 2.5-fold risk for female high school runners of sustaining a bone stress injury compared to male high school runners in cross-country. In older collegiate athletes, female cross-country runners were found to have 28.6 injuries per 100,000 athlete exposures (AE) compared to 16.4 injuries per $100,000 \mathrm{AE}$ in males, representing a 
statistically significant rate ratio of 1.8 [59]. In outdoor track (100 m-1500 m), this difference was even higher (22.3 injuries/100,000AE for females and 7.2 injuries/100,000AE for males, risk ratio of 3.1) [59]. One possible explanation that has been discussed was the association of bone stress injuries with the female athlete triad (low energy availability, menstrual disturbance and low bone mineral density) to explain the higher risk for bone stress injuries in female runners $[35,75,76]$. However, while the term female athlete triad is used only for female athletes, the more current and more detailed concept of relative energy deficiency of sports (RED-S) has also been described for male athletes [77-79]. Despite using the same initial treatment (activity modification, protected or non-weight bearing) of bone stress injuries for both sexes, the further treatment differs between female and male runners, depending on specific risk factors, such as elevated RED-S risk, biomechanics (load rates, hip adduction, rearfoot eversion), altered hormonal status or calcium and vitamin $\mathrm{D}$ intake $[14,15,73,80]$. In summary, bone stress injuries are more prevalent in female runners and treatment/rehabilitation strategies should incorporate sex as an important variable. Nonetheless, in the prevention of bone stress injuries consideration of the sex would probably benefit from awareness of RED-S, including screening for low energy availability and low mineral bone density.

\subsection{Achilles Tendinopathies Occur Twice as Often in Male Compared to Female Runners}

Data from two studies showed that male runners had almost twice the risk of having an Achilles tendinopathy as female runners $[49,51]$. This is in accordance with a systematic review on the pathogenesis of Achilles tendinopathy [81]. The Achilles tendon transmits the generated forces from the gastrocnemius-soleus muscle complex and, thus, is an important tendon for propulsion during running. However, the Achilles tendon has a poor blood supply and, therefore, is prone to overuse injuries, such as a tendinopathy [81]. The lifetime prevalence has been reported as high as $40-50 \%$ in runners $[13,82]$ and a recent 1 -year prospective study determined the incidence rate in a cohort of recreational runners to be $5.2 \%$ [51]. While the amount of loading is the key factor in the etiology of Achilles tendinopathy, there are several intrinsic (age, stress, genes, biomechanics, body composition) and extrinsic factors (footwear) modulating the risk for this injury [83]. Recent studies found biomechanical (footstrike pattern, ankle dorsiflexion moments) and training-related parameters (changes in training, cold weather, footwear, use of compression socks, mileage) as possible risk factors [10, 51, 84-86]. This summary of (possible) risk factors does not directly explain the increased probability for male runners to have an Achilles tendinopathy. Therefore, we can only speculate about the possible mechanisms.
One recently published study discusses the mechanism of the lifetime cumulated load (together with running years) which might be higher in male runners than in female runners [87]. Chronic loading needs to be taken into account when evaluating the risk for Achilles tendinopathies.

Another explanation might be found in the hormonal differences between women and men. For example, estrogen is associated with collagen synthesis and could therefore influence tendon healing capacity $[88,89]$. Furthermore, estrogen deficiency has been reported to negatively affect tendon metabolism and healing [90]. Hormonal fluctuations that are typical for the menstrual cycle have not been associated with modifications of tendon function [90,91]. A review summarizes that high or low levels of sexual hormones (estrogen, progesterone and testosterone) are not directly causing tendinopathies but may play a role in tendon pathologies [92]. Therefore, individual hormonal status should be taken into account for injury risk of female and male runners as well as for their therapies and prevention [92].

\subsection{Results of the Current Review in Contrast with and in Addition to Other Systematic Reviews}

This was the first systematic review on sex-specific differences in running injuries incorporating a meta-regression analysis to determine moderating variables and shall be discussed in light of other systematic reviews on this topic.

This systematic review contrasts the findings of the systematic review by van der Worp et al. [18], who found female runners at a lower overall risk of sustaining an injury than male runners. This finding was particularly found in men under 40 years. However, when assessing the evidence level the authors called for caution in the interpretation of their findings since these were based on only five highquality and one low-quality studies. In contrast, our review included epidemiological studies reporting injury rates separately for both sexes. With this approach, 26 studies were included and meta-analyses showed no sex differences for overall running injuries when calculated per runner or per exposure (hours or AE). Furthermore, we were able to conduct a meta-regression analysis showing a higher injury risk for female runners in competition distances of $10 \mathrm{~km}$ and shorter as well as a tendency for a higher injury risk for male runners in competition distances longer than $10 \mathrm{~km}$. This is a new finding and in line with the increased risk for male runners with a high weekly mileage ( $>64 \mathrm{~km})$, which is typically needed for longer competition distances [18].

The systematic review by Wright et al. [93] found female sex to be a primary risk factor for lower extremity bone stress injuries despite conflicting evidence using an exploratory meta-analysis incorporating three etiological studies $[6$, $94,95]$. The meta-analysis found a similar 2.3 -fold increased 
probability for female runners. Our meta-analysis supports these findings and underlines the evidence for female runners to be more prone to bone stress injuries based on five included prospective studies [24, 35, 49, 56, 59]. Female sex as a risk factor for medial tibial stress syndrome has also been described by a meta-analysis in active individuals (not exclusively runners [96]).

\subsection{Limitations and Methodological Considerations of Current Research}

This systematic review summarised data from 38 prospective studies representing more than 35,689 participants (from 36 studies) and 518,000 athlete exposures (from 2 studies). While the distribution between female and male runners (40.8-50.7\% females) was similar and no overall differences were found, breakdown of injury data regarding sex and according to location or diagnosis was only possible in six studies. Consequently, the available literature included in this systematic review did not allow conclusions on the sex-dependent epidemiology of pathologies other than bone stress injuries and Achilles tendinopathies.

The meta-regression approach of this study included several potential moderators. However, considering the multifactorial aetiology of running-related injuries, other confounding bias such as biomechanical or psychological variables may have influenced the injury risk. Another limitation was the moderate to high heterogeneity of studies included in the overall injury meta-analyses, emphasizing the need for further studies with a clear injury definition and uniform data collection methods [71, 97].

Regarding quality, future studies would benefit from documenting exposure data and using medical attention injury definitions. Furthermore, moderator analysis was only possible for 1 outcome (overall injuries per 100 runners) due to missing descriptive information on study populations (such as mileage, training duration, competition distances). As seen in Table 2, there are several different data collection methods applied and injury definitions used to determine a running injury. In accordance with recent consensus statements in injury epidemiology [71] and a Delphi consensus on running injuries [98], we encourage future running injury research to follow these guidelines to improve the homogeneity of studies. From this, future meta-analyses would benefit from comparing rates of injuries between studies $[97,99]$.

\section{Conclusion}

Sex does not seem to represent a specific risk factor when considering the overall occurrence of injuries in running. However, female runners more frequently sustain bone stress injuries, while male runners have higher risk of developing Achilles tendinopathies. Preventive measures targeting these diagnoses may therefore be more effective when accounting for sex-specific aspects such as hormonal changes or biomechanical characteristics. Regarding moderators, there is a paucity of evidence although meta-regression identified running competition distance (cut-off $10 \mathrm{~km}$ ) as a factor associated with higher injury rates in male runners.

\section{Declarations}

Funding Open Access funding enabled and organised by Projekt DEAL. The research fellowship of Karsten Hollander was funded by the German Research Foundation (Grant Number HO 6214/2-1). No sources of funding were used to assist in the preparation of this article.

Conflict of Interest Karsten Hollander, Anna Rahlf, Jan Wilke, Christopher Edler, Simon Steib, Astrid Junge and Astrid Zech have no conflicts of interest relevant to the content of this review.

Ethics approval Not applicable.

Consent to participate Not applicable.

Consent for publication Not applicable.

Data Availability Statement The data from the current study are presented in the article/electronic supplementary material and are available from the corresponding author upon request.

Code availability Not applicable.

Author Contributions KH: conceptualization, methodology, literature search, study quality assessment, formal analysis, writing (original draft preparation). ALR: conceptualization, methodology, study quality assessment, writing (review and editing). JW: formal analysis, visualization, writing (review and editing). CE: literature search, writing (review and editing). SS: conceptualization, methodology, writing (review and editing). AJ: conceptualization, methodology, study quality assessment, writing (review and editing). AZ: conceptualization, methodology, literature search, writing (review and editing), supervision. All authors read and approved the final manuscript.

Open Access This article is licensed under a Creative Commons Attribution 4.0 International License, which permits use, sharing, adaptation, distribution and reproduction in any medium or format, as long as you give appropriate credit to the original author(s) and the source, provide a link to the Creative Commons licence, and indicate if changes were made. The images or other third party material in this article are included in the article's Creative Commons licence, unless indicated otherwise in a credit line to the material. If material is not included in the article's Creative Commons licence and your intended use is not permitted by statutory regulation or exceeds the permitted use, you will need to obtain permission directly from the copyright holder. To view a copy of this licence, visit http://creativecommons.org/licenses/by/4.0/.

\section{References}

1. Pedersen BK, Saltin B. Exercise as medicine - evidence for prescribing exercise as therapy in 26 different chronic diseases. Scand 
J Med Sci Sports. 2015;25(Suppl 3):1-72. https://doi.org/10.1111/ sms.12581.

2. Pedisic Z, Shrestha N, Kovalchik S, Stamatakis E, Liangruenrom $\mathrm{N}$, Grgic J, et al. Is running associated with a lower risk of allcause, cardiovascular and cancer mortality, and is the more the better? A systematic review and meta-analysis. Br J Sports Med. 2020;54(15):898-905. https://doi.org/10.1136/bjsports-2018100493.

3. Van Middelkoop M, Kolkman J, Van Ochten J, BiermaZeinstra SM, Koes B. Prevalence and incidence of lower extremity injuries in male marathon runners. Scand $\mathrm{J}$ Med Sci Sports. 2008;18(2):140-4. https://doi.org/10.111 1/j.1600-0838.2007.00683.x.

4. Nigg BM, Baltich J, Hoerzer S, Enders H. Running shoes and running injuries: mythbusting and a proposal for two new paradigms: "preferred movement path" and "comfort filter." Br J Sports Med. 2015;49(20):1290-4. https://doi.org/10.1136/bjsports-2015-09505 4.

5. Hollander K, Baumann A, Zech A, Verhagen E. Prospective monitoring of health problems among recreational runners preparing for a half marathon. BMJ Open Sport Exerc Med. 2018;4(1):e000308. https://doi.org/10.1136/bmjsem-2017-00030 8.

6. van Mechelen W, Hlobil H, Kemper HC. Incidence, severity, aetiology and prevention of sports injuries. A review of concepts. Sports Med. 1992;14(2):82-99. https://doi.org/10.2165/00007 256-199214020-00002.

7. Buist I, Bredeweg SW, Bessem B, van Mechelen W, Lemmink KA, Diercks RL. Incidence and risk factors of running-related injuries during preparation for a 4-mile recreational running event. Br J Sports Med. 2010;44(8):598-604. https://doi.org/10.1136/ bjsm.2007.044677.

8. Ceyssens L, Vanelderen R, Barton C, Malliaras P, Dingenen B. Biomechanical risk factors associated with running-related injuries: A systematic review. Sports Med. 2019;49(7):1095-115. https://doi.org/10.1007/s40279-019-01110-z.

9. Van Middelkoop M, Kolkman J, Van Ochten J, Bierma-Zeinstra SM, Koes BW. Risk factors for lower extremity injuries among male marathon runners. Scand J Med Sci Sports. 2008;18(6):6917. https://doi.org/10.1111/j.1600-0838.2007.00768.x.

10. Hollander K, Johnson CD, Outerleys J, Davis IS. Multifactorial determinants of running injury locations in 550 injured recreational runners. Med Sci Sports Exerc. 2021;53(1):103-7. https ://doi.org/10.1249/MSS.0000000000002455 (accepted for publication).

11. Hoenig T, Rolvien T, Hollander K. Footstrike patterns in runners: concepts, classifications, techniques, and implicationsfor runningrelated injuries. Dtsch Z Sportmed. 2020;71(3):55-61. https://doi. org/10.5960/dzsm.2020.424.

12. Vannatta CN, Heinert BL, Kernozek TW. Biomechanical risk factors for running-related injury differ by sample population: a systematic review and meta-analysis. Clin Biomech (Bristol, Avon). 2020;75:104991. https://doi.org/10.1016/j.clinbiomec h.2020.104991.

13. Kujala UM, Sarna S, Kaprio J. Cumulative incidence of achilles tendon rupture and tendinopathy in male former elite athletes. Clin J Sport Med. 2005;15(3):133-5. https://doi.org/10.1097/01. jsm.0000165347.55638.23.

14. Davis IS, Bowser BJ, Mullineaux DR. Greater vertical impact loading in female runners with medically diagnosed injuries: a prospective investigation. Br J Sports Med. 2016;50(14):887-92. https://doi.org/10.1136/bjsports-2015-094579.

15. Milner CE, Hamill J, Davis IS. Distinct hip and rearfoot kinematics in female runners with a history of tibial stress fracture. J Orthop Sports Phys Ther. 2010;40(2):59-66. https://doi. org/10.2519/jospt.2010.3024.
16. Duckham RL, Brooke-Wavell K, Summers GD, Cameron N, Peirce N. Stress fracture injury in female endurance athletes in the United Kingdom: a 12-month prospective study. Scand J Med Sci Sports. 2015;25(6):854-9. https://doi.org/10.1111/ sms.12453.

17. McKean KA, Manson NA, Stanish WD. Musculoskeletal injury in the masters runners. Clin J Sport Med. 2006;16(2):149-54. https ://doi.org/10.1097/00042752-200603000-00011.

18. van der Worp MP, ten Haaf DS, van Cingel R, de Wijer A, Nijhuis-van der Sanden MW, Staal JB. Injuries in runners; a systematic review on risk factors and sex differences. PLoS ONE. 2015;10(2):e0114937. https://doi.org/10.1371/journal.pone.01149 37.

19. Edouard P, Feddermann-Demont N, Alonso JM, Branco P, Junge A. Sex differences in injury during top-level international athletics championships: surveillance data from 14 championships between 2007 and 2014. Br J Sports Med. 2015;49(7):472-7. https://doi. org/10.1136/bjsports-2014-094316.

20. Prien A, Grafe A, Rossler R, Junge A, Verhagen E. Epidemiology of head injuries focusing on concussions in team contact sports: a systematic review. Sports Med. 2018;48(4):953-69. https://doi. org/10.1007/s40279-017-0854-4.

21. Hewett TE, Myer GD, Ford KR. Anterior cruciate ligament injuries in female athletes: Part 1, mechanisms and risk factors. Am J Sports Med. 2006;34(2):299-311. https://doi.org/10.1177/03635 46505284183.

22. Doherty C, Delahunt E, Caulfield B, Hertel J, Ryan J, Bleakley C. The incidence and prevalence of ankle sprain injury: a systematic review and meta-analysis of prospective epidemiological studies. Sports Med. 2014;44(1):123-40. https://doi.org/10.1007/s4027 9-013-0102-5.

23. Moher D, Liberati A, Tetzlaff J, Altman DG, Group P. Preferred reporting items for systematic reviews and meta-analyses: the PRISMA statement. PLoS Med. 2009;6(7):e1000097. https://doi. org/10.1371/journal.pmed.1000097.

24. Changstrom BG, Brou L, Khodaee M, Braund C, Comstock RD. Epidemiology of stress fracture injuries among US high school athletes, 2005-2006 through 2012-2013. Am J Sports Med. 2015;43(1):26-33. https://doi.org/10.1177/0363546514562739.

25. Downs SH, Black N. The feasibility of creating a checklist for the assessment of the methodological quality both of randomised and non-randomised studies of health care interventions. J Epidemiol Community Health. 1998;52(6):377-84.

26. Hollander K, Zech A, Rahlf AL, Orendurff MS, Stebbins J, Heidt $\mathrm{C}$. The relationship between static and dynamic foot posture and running biomechanics: a systematic review and meta-analysis. Gait Posture. 2019;72:109-22. https://doi.org/10.1016/j.gaitp ost.2019.05.031.

27. DerSimonian R, Laird N. Meta-analysis in clinical trials. Control Clin Trials. 1986;7(3):177-88. https://doi.org/10.1016/01972456(86)90046-2.

28. Higgins J, Thomas J, Chandler J, Cumpston M, Li T, Page M, et al. Cochrane handbook for systematic reviews of interventions version 6.0 (updated July 2019). 2nd ed. Chichester: Wiley; 2019.

29. Wilke J, Muller AL, Giesche F, Power G, Ahmedi H, Behm DG. Acute effects of foam rolling on range of motion in healthy adults: a systematic review with multilevel meta-analysis. Sports Med. 2020;50(2):387-402. https://doi.org/10.1007/s40279-019-01205 $-7$.

30. Şahin M, Aybek E. Jamovi: an easy to use statistical software for the social scientists. Int J Assess Tools Educ. 2019. https://doi. org/10.21449/ijate.661803.

31. Alonso JM, Edouard P, Fischetto G, Adams B, Depiesse F, Mountjoy M. Determination of future prevention strategies in elite track and field: analysis of Daegu 2011 IAAF Championships injuries 
and illnesses surveillance. Br J Sports Med. 2012;46(7):505-14. https://doi.org/10.1136/bjsports-2012-091008.

32. Alonso JM, Junge A, Renstrom P, Engebretsen L, Mountjoy M, Dvorak J. Sports injuries surveillance during the 2007 IAAF World Athletics Championships. Clin J Sport Med. 2009;19(1):26-32. https://doi.org/10.1097/JSM.0b013e3181 $91 \mathrm{c} 8 \mathrm{e} 7$.

33. Alonso JM, Tscholl PM, Engebretsen L, Mountjoy M, Dvorak $\mathrm{J}$, Junge A. Occurrence of injuries and illnesses during the 2009 IAAF World Athletics Championships. Br J Sports Med. 2010;44(15):1100-5. https://doi.org/10.1136/bjsm.2010.078030.

34. Beachy G, Akau CK, Martinson M, Olderr TF. High school sports injuries. A longitudinal study at Punahou School: 1988 to 1996. Am J Sports Med. 1997;25(5):675-81. https://doi. org/10.1177/036354659702500515.

35. Bennell KL, Malcolm SA, Thomas SA, Wark JD, Brukner PD. The incidence and distribution of stress fractures in competitive track and field athletes. A twelve-month prospective study. Am J Sports Med. 1996;24(2):211-7. https://doi.org/10.1177/03635 4659602400217.

36. Colbert LH, Hootman JM, Macera CA. Physical activity-related injuries in walkers and runners in the aerobics center longitudinal study. Clin J Sport Med. 2000;10(4):259-63. https://doi. org/10.1097/00042752-200010000-00006.

37. Dane S, Can S, Gursoy R, Ezirmik N. Sport injuries: relations to sex, sport, injured body region. Percept Mot Skills. 2004;98(2):519-24. https://doi.org/10.2466/pms.98.2.519-524.

38. de Loes M, Goldie I. Incidence rate of injuries during sport activity and physical exercise in a rural Swedish municipality: incidence rates in 17 sports. Int J Sports Med. 1988;9(6):461-7. https ://doi.org/10.1055/s-2007-1025052.

39. Edouard P, Depiesse F, Branco P, Alonso JM. Analyses of Helsinki 2012 European Athletics Championships injury and illness surveillance to discuss elite athletes risk factors. Clin J Sport Med. 2014;24(5):409-15. https://doi.org/10.1097/JSM.0000000000 000052.

40. Edouard P, Depiesse F, Hertert P, Branco P, Alonso JM. Injuries and illnesses during the 2011 Paris European Athletics Indoor Championships. Scand J Med Sci Sports. 2013;23(4):e213-8. https://doi.org/10.1111/sms.12027.

41. Edouard P, Navarro L, Branco P, Gremeaux V, Timpka T, Junge A. Injury frequency and characteristics (location, type, cause and severity) differed significantly among athletics ('track and field') disciplines during 14 international championships (2007-2018): implications for medical service planning. Br J Sports Med. 2020;54(3):159-67. https://doi.org/10.1136/bjsports-2019-10071 7.

42. Fokkema T, de Vos RJ, van Ochten JM, Verhaar JAN, Davis IS, Bindels PJE, et al. Online multifactorial prevention programme has no effect on the number of running-related injuries: a randomised controlled trial. Br J Sports Med. 2019;53(23):1479-85. https://doi.org/10.1136/bjsports-2018-099744.

43. Hayes LE, Boulos A, Cruz AI Jr. Risk factors for in-season injury in varsity collegiate cross-country athletes: an analysis of one season in 97 athletes. J Sports Med Phys Fitness. 2019;59(9):153643. https://doi.org/10.23736/S0022-4707.19.09221-1.

44. Hespanhol Junior LC, van Mechelen W, Verhagen E. Health and economic burden of running-related injuries in Dutch trailrunners: a prospective cohort study. Sports Med. 2017;47(2):367-77. https ://doi.org/10.1007/s40279-016-0551-8.

45. Hespanhol Junior LC, van Mechelen W, Postuma E, Verhagen E. Health and economic burden of running-related injuries in runners training for an event: a prospective cohort study. Scand J Med Sci Sports. 2016;26(9):1091-9. https://doi.org/10.1111/ sms. 12541
46. Hofstede H, Franke TPC, van Eijk RPA, Backx FJG, Kemler E, Huisstede BMA. In training for a marathon: runners and runningrelated injury prevention. Phys Ther Sport. 2020;41:80-6. https:// doi.org/10.1016/j.ptsp.2019.11.006.

47. Hughes WA, Noble HB, Porter M. Distance race injuries: an analysis of runners' perceptions. Phys Sportsmed. 1985;13(11):43-58. https://doi.org/10.1080/00913847.1985.11708924.

48. Jacobsson J, Timpka T, Kowalski J, Nilsson S, Ekberg J, Dahlstrom $\mathrm{O}$, et al. Injury patterns in Swedish elite athletics: annual incidence, injury types and risk factors. Br J Sports Med. 2013;47(15):941-52. https://doi.org/10.1136/bjsports-2012-09165 1.

49. Johansson C. Injuries in elite orienteers. Am J Sports Med. 1986;14(5):410-5. https://doi.org/10.1177/036354658601400515.

50. Kluitenberg B, van Middelkoop M, Smits DW, Verhagen E, Hartgens F, Diercks R, et al. The NLstart2run study: Incidence and risk factors of running-related injuries in novice runners. Scand J Med Sci Sports. 2015;25(5):e515-23. https://doi.org/10.1111/ sms. 12346.

51. Lagas IF, Fokkema T, Verhaar JAN, Bierma-Zeinstra SMA, van Middelkoop M, de Vos RJ. Incidence of Achilles tendinopathy and associated risk factors in recreational runners: a large prospective cohort study. J Sci Med Sport. 2020;23(5):448-52. https://doi. org/10.1016/j.jsams.2019.12.013.

52. McLain LG, Reynolds S. Sports injuries in a high school. Pediatrics. 1989;84(3):446-50.

53. Messier SP, Martin DF, Mihalko SL, Ip E, DeVita P, Cannon DW, et al. A 2-year prospective cohort study of overuse running injuries: the runners and injury longitudinal study (TRAILS). Am J Sports Med. 2018;46(9):2211-21. https://doi.org/10.1177/03635 46518773755.

54. Nicholl JP, Williams BT. Injuries sustained by runners during a popular marathon. Br J Sports Med. 1983;17(1):10-5. https://doi. org/10.1136/bjsm.17.1.10.

55. Nielsen RO, Parner ET, Nohr EA, Sorensen H, Lind M, Rasmussen $\mathrm{S}$. Excessive progression in weekly running distance and risk of running-related injuries: an association which varies according to type of injury. J Orthop Sports Phys Ther. 2014;44(10):739-47. https://doi.org/10.2519/jospt.2014.5164.

56. Plisky MS, Rauh MJ, Heiderscheit B, Underwood FB, Tank RT. Medial tibial stress syndrome in high school cross-country runners: incidence and risk factors. J Orthop Sports Phys Ther. 2007;37(2):40-7. https://doi.org/10.2519/jospt.2007.2343.

57. Rauh MJ, Koepsell TD, Rivara FP, Margherita AJ, Rice SG. Epidemiology of musculoskeletal injuries among high school crosscountry runners. Am J Epidemiol. 2006;163(2):151-9. https://doi. org/10.1093/aje/kwj022.

58. Rauh MJ, Margherita AJ, Rice SG, Koepsell TD, Rivara FP. High school cross country running injuries: a longitudinal study. Clin J Sport Med. 2000;10(2):110-6. https://doi.org/10.1097/00042 752-200004000-00005

59. Rizzone KH, Ackerman KE, Roos KG, Dompier TP, Kerr ZY. The epidemiology of stress fractures in collegiate student-athletes, 2004-2005 through 2013-2014 academic years. J Athl Train. 2017;52(10):966-75. https://doi.org/10.4085/1062-6050-52.8.01.

60. Ruffe NJ, Sorce SR, Rosenthal MD, Rauh MJ. Lower quarter- and upper quarter $\mathrm{Y}$ balance tests as predictors of running-related injuries in high school cross-country runners. Int J Sports Phys Ther. 2019;14(5):695-706.

61. Steinacker T, Steuer M, Holtke V. Orthopedic problems in older marathon runners. Sportverletz Sportschaden. 2001;15(1):12-5. https://doi.org/10.1055/s-2001-11962.

62. Lynam DR, Whiteside S, Jones S. Self-reported psychopathy: a validation study. J Pers Assess. 1999;73(1):110-32. https://doi. org/10.1207/S15327752JPA730108. 
63. Walter SD, Hart LE, McIntosh JM, Sutton JR. The Ontario cohort study of running-related injuries. Arch Intern Med. 1989;149(11):2561-4.

64. Winter SC, Gordon S, Brice SM, Lindsay D, Barrs S. Overuse injuries in runners of different abilities-a one-year prospective study. Res Sports Med. 2019. https://doi.org/10.1080/15438 627.2019.1616548.

65. Winter SC, Gordon S, Brice SM, Lindsay D, Barrs S. A multifactorial approach to overuse running injuries: a 1-year prospective study. Sports Health. 2020;12(3):296-303. https://doi. org/10.1177/1941738119888504.

66. van Gent RN, Siem D, van Middelkoop M, van Os AG, BiermaZeinstra SM, Koes BW. Incidence and determinants of lower extremity running injuries in long distance runners: a systematic review. Br J Sports Med. 2007;41(8):469-80. https://doi. org/10.1136/bjsm.2006.033548.

67. van Poppel D, de Koning J, Verhagen AP, Scholten-Peeters GG. Risk factors for lower extremity injuries among half marathon and marathon runners of the Lage Landen Marathon Eindhoven 2012: a prospective cohort study in the Netherlands. Scand J Med Sci Sports. 2016;26(2):226-34. https://doi.org/10.1111/ sms. 12424

68. Malisoux L, Delattre N, Urhausen A, Theisen D. Shoe cushioning influences the running injury risk according to body mass: a randomized controlled trial involving 848 recreational runners. Am J Sports Med. 2020;48(2):473-80. https://doi.org/10.1177/03635 46519892578.

69. Hollander K, Heidt C, Babette CVDZ, Braumann KM, Zech A. Long-term effects of habitual barefoot running and walking: a systematic review. Med Sci Sports Exerc. 2017;49(4):752-62. https://doi.org/10.1249/MSS.0000000000001141.

70. Krabak BJ, Roberts WO, Tenforde AS, Ackerman KE, Adami PE, Baggish AL, et al. Youth running consensus statement: minimising risk of injury and illness in youth runners. Br J Sports Med. 2020. https://doi.org/10.1136/bjsports-2020-102518.

71. Bahr R, Clarsen B, Derman W, Dvorak J, Emery CA, Finch CF, et al. International Olympic Committee consensus statement: methods for recording and reporting of epidemiological data on injury and illness in sport 2020 (including STROBE Extension for Sport Injury and Illness Surveillance (STROBE-SIIS)). Br J Sports Med. 2020;54(7):372-89. https://doi.org/10.1136/bjspo rts-2019-101969.

72. Soligard T, Schwellnus M, Alonso JM, Bahr R, Clarsen B, Dijkstra HP, et al. How much is too much? (Part 1) International Olympic Committee consensus statement on load in sport and risk of injury. Br J Sports Med. 2016;50(17):1030-41. https://doi. org/10.1136/bjsports-2016-096581.

73. Lin CY, Casey E, Herman DC, Katz N, Tenforde AS. Sex differences in common sports injuries. PM R. 2018;10(10):1073-82. https://doi.org/10.1016/j.pmrj.2018.03.008.

74. Hoenig T, Tenforde A, Strahl A, Rolvien T, Hollander K. Does MRI grading correlate with return to sports following bone stress injuries? A systematic review and meta-analysis. Am J Sports Med. 2021; (accepted for publication).

75. Rauh MJ, Barrack M, Nichols JF. Associations between the female athlete triad and injury among high school runners. Int J Sports Phys Ther. 2014;9(7):948-58.

76. Tenforde AS, Carlson JL, Chang A, Sainani KL, Shultz R, Kim $\mathrm{JH}$, et al. Association of the female athlete triad risk assessment stratification to the development of bone stress injuries in collegiate athletes. Am J Sports Med. 2017;45(2):302-10. https://doi. org/10.1177/0363546516676262.

77. Mountjoy M, Sundgot-Borgen J, Burke L, Ackerman KE, Blauwet $\mathrm{C}$, Constantini N, et al. International Olympic Committee (IOC) consensus statement on Relative Energy Deficiency in
Sport (RED-S): 2018 update. Int J Sport Nutr Exerc Metab. 2018;28(4):316-31. https://doi.org/10.1123/ijsnem.2018-0136.

78. Tenforde AS, Parziale AL, Popp KL, Ackerman KE. Low bone mineral density in male athletes is associated with bone stress injuries at anatomic sites with greater trabecular composition. Am J Sports Med. 2018;46(1):30-6. https://doi.org/10.1177/03635 46517730584.

79. Tenforde AS, Beauchesne AR, Borg-Stein J, Hollander K, McInnis K, Kotler D, et al. Awareness and comfort treating the female athlete triad and relative energy deficency in sport among healthcare p-roviders. Dtsch Z Sportmed. 2020;71(3):76-80. https://doi. org/10.5960/dzsm.2020.422.

80. Bredeweg SW, Kluitenberg B, Bessem B, Buist I. Differences in kinetic variables between injured and noninjured novice runners: a prospective cohort study. J Sci Med Sport. 2013;16(3):205-10. https://doi.org/10.1016/j.jsams.2012.08.002.

81. Magnan B, Bondi M, Pierantoni S, Samaila E. The pathogenesis of Achilles tendinopathy: a systematic review. Foot Ankle Surg. 2014;20(3):154-9. https://doi.org/10.1016/j.fas.2014.02.010.

82. Lopes AD, Hespanhol Junior LC, Yeung SS, Costa LO. What are the main running-related musculoskeletal injuries? A systematic review. Sports Med. 2012;42(10):891-905. https ://doi.org/10.2165/11631170-000000000-00000 (10.1007/ BF03262301)

83. Cook JL, Purdam CR. Is tendon pathology a continuum? A pathology model to explain the clinical presentation of load-induced tendinopathy. Br J Sports Med. 2009;43(6):409-16. https://doi. org/10.1136/bjsm.2008.051193.

84. Kernozek TW, Knaus A, Rademaker T, Almonroeder TG. The effects of habitual foot strike patterns on Achilles tendon loading in female runners. Gait Posture. 2018;66:283-7. https://doi. org/10.1016/j.gaitpost.2018.09.016.

85. Asplund CA, Best TM. Achilles tendon disorders. BMJ. 2013;346:f1262. https://doi.org/10.1136/bmj.f1262.

86. Wearing SC, Davis IS, Brauner T, Hooper SL, Horstmann T. Do habitual foot-strike patterns in running influence functional Achilles tendon properties during gait? J Sports Sci. 2019;37(23):273543. https://doi.org/10.1080/02640414.2019.1663656.

87. Lieberthal K, Paterson KL, Cook J, Kiss Z, Girdwood M, Bradshaw EJ. Prevalence and factors associated with asymptomatic Achilles tendon pathology in male distance runners. Phys Ther Sport. 2019;39:64-8. https://doi.org/10.1016/j.ptsp.2019.06.006.

88. Bryant AL, Clark RA, Bartold S, Murphy A, Bennell KL, Hohmann E, et al. Effects of estrogen on the mechanical behavior of the human Achilles tendon in vivo. J Appl Physiol (1985). 2008;105(4):1035-43. https://doi.org/10.1152/japplphysiol.01281 .2007.

89. Leblanc DR, Schneider M, Angele P, Vollmer G, Docheva D. The effect of estrogen on tendon and ligament metabolism and function. J Steroid Biochem Mol Biol. 2017;172:106-16. https://doi. org/10.1016/j.jsbmb.2017.06.008.

90. Oliva F, Piccirilli E, Berardi AC, Frizziero A, Tarantino U, Maffulli N. Hormones and tendinopathies: the current evidence. $\mathrm{Br}$ Med Bull. 2016;117(1):39-58. https://doi.org/10.1093/bmb/ldv05 4.

91. Kubo K, Miyamoto M, Tanaka S, Maki A, Tsunoda N, Kanehisa H. Muscle and tendon properties during menstrual cycle. Int J Sports Med. 2009;30(2):139-43. https://doi.org/10.1055/s-0028-11045 73.

92. Abate M, Guelfi M, Pantalone A, Vanni D, Schiavone C, Andia I, et al. Therapeutic use of hormones on tendinopathies: a narrative review. Muscles Ligaments Tendons J. 2016;6(4):445-52. https ://doi.org/10.11138/mltj/2016.6.4.445.

93. Wright AA, Taylor JB, Ford KR, Siska L, Smoliga JM. Risk factors associated with lower extremity stress fractures in runners: a systematic review with meta-analysis. Br J Sports Med. 
2015;49(23):1517-23. https://doi.org/10.1136/bjsports-2015094828.

94. Tenforde AS, Sayres LC, McCurdy ML, Sainani KL, Fredericson M. Identifying sex-specific risk factors for stress fractures in adolescent runners. Med Sci Sports Exerc. 2013;45(10):1843-51. https://doi.org/10.1249/MSS.0b013e3182963d75.

95. Yagi S, Muneta T, Sekiya I. Incidence and risk factors for medial tibial stress syndrome and tibial stress fracture in high school runners. Knee Surg Sports Traumatol Arthrosc. 2013;21(3):556-63. https://doi.org/10.1007/s00167-012-2160-x.

96. Reinking MF, Austin TM, Richter RR, Krieger MM. Medial Tibial stress syndrome in active individuals: a systematic review and meta-analysis of risk factors. Sports Health. 2017;9(3):252-61. https://doi.org/10.1177/1941738116673299.

97. Timpka T, Alonso JM, Jacobsson J, Junge A, Branco P, Clarsen B, et al. Injury and illness definitions and data collection procedures for use in epidemiological studies in Athletics (track and field): consensus statement. Br J Sports Med. 2014;48(7):483-90. https ://doi.org/10.1136/bjsports-2013-093241.

98. Yamato TP, Saragiotto BT, Lopes AD. A consensus definition of running-related injury in recreational runners: a modified Delphi approach. J Orthop Sports Phys Ther. 2015;45(5):375-80. https ://doi.org/10.2519/jospt.2015.5741.

99. Yamato TP, Saragiotto BT, Hespanhol Junior LC, Yeung SS, Lopes AD. Descriptors used to define running-related musculoskeletal injury: a systematic review. J Orthop Sports Phys Ther. 2015;45(5):366-74. https://doi.org/10.2519/jospt.2015.5750.

\section{Affiliations}

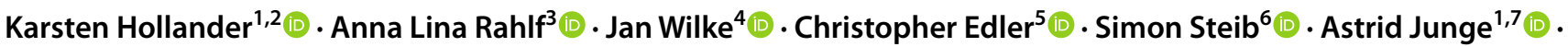 Astrid Zech ${ }^{3}$ (D)}

1 Medical School Hamburg, Hamburg, Germany

2 Department of Physical Medicine and Rehabilitation, Spaulding National Running Center, Harvard Medical School, Cambridge, MA, USA

3 Department of Human Movement Science and Exercise Physiology, Institute of Sport Science, Friedrich Schiller University Jena, Jena, Germany

4 Department of Sports Medicine and Exercise Physiology, Goethe University Frankfurt, Frankfurt, Germany
5 Prevention, Rehabilitation and Interdisciplinary Sports Medicine, BG Trauma Hospital of Hamburg, Hamburg, Germany

6 Department of Human Movement, Training and Active Aging, Institute of Sports and Sports Science, Heidelberg University, Heidelberg, Germany

7 Swiss Concussion Center, Schulthess Klinik, Zürich, Switzerland 